\title{
Mudanças e Permanências na Cultura Política das Metrópoles Brasileiras
}

Sérgio de Azevedo

Orlando Alves dos Santos Junior

Luiz César de Queiroz Ribeiro

\begin{abstract}
relação entre as esferas econômica e cultural nas ciências sociais A permite uma miríade de abordagens teóricas. Recentemente, vários são os cientistas sociais que vêm apontando mudanças nas atitudes e nos valores que orientavam o comportamento político relacionado à cidadania convencional (Marshall, 1967) nas sociedades mais avançadas do capitalismo como consequência das mudanças estruturais iniciadas na segunda metade da década de 1970, com a reestruturação produtiva e a globalização econômica (ver, entre outros, Bauman, 1999; Boschi, 2004; Castel, 1998; Harvey, 1993; Putnam, 2000; Turner, 1990). Os efeitos de tais mudanças estariam gerando a emergência de comportamentos políticos orientados por novos valores, crenças e disposições sociais, abarcando tanto elementos considerados tradicionalmente conservadores - adesão ao liberalismo econômico e consequente diminuição da função reguladora do Estado - quanto valores considerados progressistas - defesa de direitos socioculturais difusos (meio ambiente, igualdade de gênero, liberdade de orientação sexual etc.) e novas formas de participação social e política (participação em redes, apoio a organizações não governamentais (ONGs), boicote a produtos nocivos ao meio ambiente, denúncias de empresas que utilizam mão de obra infantil, campanhas humanitárias etc.).
\end{abstract}

Reconhecendo a complexidade desse debate, a proposta deste artigo é discutir aquilo que vem sendo denominado pela literatura de nova

DADOS - Revista de Ciências Sociais, Rio de Janeiro, Vol. 52, n-3, 2009, pp. 691 a 733. 
cultura política (NCP), cujo principal formulador é o sociólogo Terry Clark (ver, entre outros, Clark e Inglehart, 2007; Clark e HoffmannMartinot, 1998; e Clark e Navarro, 2007), e avaliar os limites e as possibilidades dessa abordagem para interpretar a cultura política brasileira contemporânea ${ }^{1}$. O centro de nossa preocupação teórica está vinculado, de modo especial, à compreensão do significado desses processos sobre as metrópoles como expressão das áreas mais modernas da sociedade brasileira e à discussão em torno da existência de um possível "efeito metrópole" sobre a cultura política, sobretudo nos aspectos relacionados à NCP.

De fato, na formulação dos autores mencionados, a NCP estaria se fortalecendo e se difundindo, nas últimas décadas, sob os efeitos dos processos de globalização econômica e cultural, especialmente nos países desenvolvidos, sem, contudo, ser a única ou mesmo a principal gramática política existente, competindo com outras, tais como o corporativismo, o clientelismo e o populismo. Seria esperado que esses efeitos fossem mais visíveis exatamente nas áreas metropolitanas, por serem o principal locus do processo de modernização das sociedades de mercado, estejam elas situadas nos países desenvolvidos ou nos países em desenvolvimento, ainda que, nesses últimos, a NCP deva aparecer concomitantemente a outras formas de expressão política relacionadas às dinâmicas de segregação social. Como explicitaremos ao longo deste artigo, tomando como parâmetro o caso brasileiro, entendemos que a abordagem da NCP apresenta diversas limitações para a análise dos países emergentes.

Visando dar conta da complexidade e da importância dessa reflexão, dividimos o artigo em quatro seções. Na primeira, são realizadas algumas considerações teóricas sobre a relação entre cultura política e a cidade em nossa contemporaneidade. Em seguida, discutimos o conceito de NCP e os limites de sua aplicação ao contexto brasileiro. Na terceira seção, dedicamo-nos à reflexão da especificidade da cultura política brasileira, com base em pesquisas empíricas recentes realizadas nacionalmente e em várias metrópoles ${ }^{2}$, abordando aspectos relacionados a valores e a percepções em torno da cidadania e a práticas associativas e de mobilização sociopolítica no Brasil. Por fim, na última seção, fazemos um balanço sobre o tema tratado.

Essa reflexão permite uma instigante perspectiva analítica sobre a relação entre as transformações dos valores e as atitudes dos cidadãos 
quanto à democracia e ao fato metropolitano como morfologia social e cultural. As pesquisas empíricas realizadas suscitam, com efeito, pistas interessantes para considerações sobre a sociabilidade inerente ao modo de vida engendrado pela grande cidade na contemporaneidade, que parece radicalizar o racionalismo, o individualismo e a fluidez das relações sociais já detectados por clássicos da sociologia, como Weber (1999; 2004) e Simmel (1979).

\section{NOVA CULTURA POLÍTICA: CONCEITUAÇÃO E IDIOSSINCRASIAS DO CASO BRASILEIRO}

Pelas análises dos autores que defendem a emergência da NCP - entre os quais se enquadram também Manuel Villaverde Cabral e Filipe Carreira da Silva (Cabral e Silva, 2007) -, essa nova cidadania política, segundo nossa leitura, associaria valores pós-modernos, com ênfase na defesa dos direitos individuais, maior tolerância a diferentes padrões de comportamento, abertura para experimentação no plano individual, menor grau de subordinação às normas preconizadas pelo Estado (com uma diminuição da valorização, entre outros, do pagamento de imposto e da prestação do serviço militar como expressão do bom exercício da cidadania moderna), geralmente acompanhados de certo conservadorismo no nível de políticas econômicas. Em outras palavras, no que concerne à cidadania, as tensões existentes (Reis, 2000) entre as dimensões civil (direitos individuais) e cívica (direitos coletivos) tendem a se acirrar na denominada NCP da pós-modernidade.

Nesse sentido, poderíamos dizer que, nas áreas mais urbanizadas, caracterizadas pela heterogeneidade social e habitadas por classes e grupos com maior capacidade de poder político e econômico, tenderiam a prevalecer traços dessa cidadania pós-moderna, em contraposição às demais áreas urbanas, que manteriam maior cristalização dos valores da cidadania clássica hegemônica desde o século passado, composta de suas dimensões civil, política e social. Em outras palavras, segundo a abordagem descrita, seria lícito concluir, como afirma Cabral (2000), que, hoje, o exercício dos direitos de cidadania tenderia a se manifestar de forma mais expressiva por meio da "geometria variável" da automobilização do que pelo associativismo clássico, vinculado, fundamentalmente, às formas convencionais de capital social.

Podemos dizer que a NCP tem sua origem nas transformações políticas, econômicas, sociais, culturais e institucionais associadas à globali- 
zação, tendo forte relação com a ascensão de valores pós-materialistas em sociedades que alcançaram níveis de desenvolvimento econômico. Segundo Clark e Inglehart (2007), a NCP ${ }^{3}$ se caracterizaria por sete elementos-chave: (i) modificação da dimensão clássica entre direita e esquerda; (ii) explícita separação entre questões sociais e econômico-fiscais; (iii) questões sociais têm crescimento e importância relativamente maiores do que as econômicas; (iv) crescimento concomitante do individualismo de mercado e da responsabilidade social; (v) questionamentos ao Estado de bem-estar social; (vi) emergência de políticas centradas em questões-chave e ampliação da participação cidadã, por um lado, e declínio das organizações políticas hierárquicas, por outro; e (vii) existência dos mais fervorosos defensores da NCP nas sociedades menos hierárquicas e entre os indivíduos mais jovens, mais instruídos e os que vivem mais confortavelmente.

Cabe, agora, contrastar cada uma dessas características com o contexto brasileiro:

(i) Modificação da dimensão clássica entre direita e esquerda. A NCP tem relação com o enfraquecimento da clivagem esquerda-direita como fundamento da disputa política. Partindo de uma associação da esquerda, com um posicionamento progressista nos âmbitos social e fiscal (econômico), e da direita, com um posicionamento conservador nos âmbitos social e fiscal (econômico), a NCP se caracterizaria por um posicionamento diferente: progressista/liberal no âmbito social e conservador no âmbito fiscal (econômico). A questão é que, enquanto, no contexto europeu, a divisão entre direita e esquerda tradicionalmente organizou - e, em certa medida, permanece balizando - o comportamento político e cultural da sociedade, no Brasil, em contraposição, essa clivagem somente fazia sentido para a pequena parcela da população detentora da cultura letrada e para a que se encontrava organizada nas formas associativas relacionadas ao trabalho assalariado urbano de alta qualificação ou do setor público. A maior parte da população movia-se regida por outras gramáticas políticas e culturais, merecendo destaque o clientelismo, o corporativismo e o populismo (Nunes, 1997). A questão seria discutir em que medida esses elementos conformariam uma predisposição favorável à adoção de valores e práticas associados à NCP, como a crença no individualismo orientando o comportamento político. 
(ii) Explícita separação entre questões sociais e econômico-fiscais. Nas sociedades que alcançaram certo grau de igualitarismo, a agenda social tende a pressionar menos a agenda econômico-fiscal (considerando-se os temas da maior participação das mulheres, do multiculturalismo, da liberdade de orientação sexual e da questão ambiental; esta última com fortes impactos sobre a dinâmica econômica). No caso brasileiro, ainda que haja espaço para esse tipo de agenda, em razão de também observarmos nítidas mudanças socioculturais semelhantes àquelas observadas nos países desenvolvidos, as demandas sociais baseadas em objetivos redistributivos permanecem pressionando fortemente as políticas econômica e fiscal, tendo em vista o grau de carência e as desigualdades sociais que vigoram no Brasil. No entanto, é preciso reconhecer mudanças no significado e no sentido dessa agenda. A construção da agenda reformista no país, da redemocratização nos anos que antecederam a elaboração da Constituição de 1988 até os anos 1990, foi resultado de um processo paralelo de atuação de vários movimentos sociais e da elaboração de uma bibliografia crítica em torno da questão social brasileira. A partir dos anos 1990, essa agenda passa a sofrer mudanças decorrentes dos ajustes macroeconômicos de corte neoliberal, fazendo com que a questão redistributiva perca importância relativa, não obstante sua pertinência social, passando-se a priorizar políticas distributivas focalizadas nos grupos sociais mais vulneráveis.

(iii) Questões sociais têm crescimento e importância relativamente maiores do que as econômicas. Essa característica tem, segundo os autores que formulam a teoria da NCP, forte relação com a situação de prosperidade econômica alcançada nos países do Primeiro Mundo, o que levaria a uma preocupação mais ligada ao estilo e à qualidade de vida em face das necessidades econômicas tradicionais. No Brasil, ao contrário, as necessidades econômicas tradicionais, voltadas para a reprodução social, permanecem tendo grande relevância na agenda política.

(iv) Crescimento concomitante do individualismo de mercado e da responsabilidade social. Segundo os mesmos autores, a NCP juntaria o liberalismo econômico - mais associado aos partidos conservadores - com o progressismo social - identificado, tradicionalmente, com os partidos de esquerda. De fato, a NCP também expressa a perda do posicionamento político referido ao pertencimento das classes sociais. No passado, a classe trabalhadora (de menor renda e de menor grau de instrução) tenderia a votar na esquerda, enquanto as classes média e alta (de 
maior instrução e de maior renda) tenderiam a votar na direita. No contexto atual, haveria uma tendência de as classes trabalhadoras votarem mais na direita e as classes média e alta votarem mais na esquerda. No caso do Brasil, mesmo com nuanças e talvez sem a direta associação com a dualidade esquerda-direita, observa-se tendência similar de fortalecimento dos partidos e líderes que associam o liberalismo econômico ao progressismo social.

(v) Questionamentos ao Estado de bem-estar social. A NCP põe em questão a eficiência do planejamento centralizado e dos serviços públicos prestados por grandes burocracias governamentais, propondo a descentralização político-administrativa para níveis de governo local e mesmo para esferas da sociedade. Podemos observar relativa difusão de valores semelhantes no Brasil, já que é nítido o processo de descentralização e de valorização do poder local. Ao mesmo tempo, por um lado, percebe-se, nos últimos cinco anos, o revigoramento da crença no planejamento público; por outro, a disputa sobre o sentido e o conteúdo da descentralização, que se torna objeto de polêmicas e de competição entre os atores sociais mobilizados.

(vi) Emergência de políticas centradas em questões-chave e ampliação da participação cidadã, por um lado, e declínio das organizações políticas hierárquicas, por outro. A NCP tem relação com o enfraquecimento das hierarquias sociais como fundamento sobre os comportamentos políticos, decorrente dos movimentos sociais que se organizaram em oposição às hierarquias políticas, ainda prevalecentes em alguns países. Tal fato tem grande importância para a dinâmica partidária - os líderes tenderiam a se relacionar diretamente com a cidadania, e os partidos, a submeter suas decisões e escolhas aos cidadãos. Dessa perspectiva, poderíamos dizer que a NCP poderia ser associada ao processo de perda das identidades convencionais / tradicionais que caracterizam a cidadania na modernidade capitalista - que possibilitavam a filiação associativa às organizações clássicas, como os sindicatos e as associações de bairro -, ao movimento de fragmentação do sujeito e ao processo de constituição de múltiplas identidades que caracteriza a pós-modernidade (Harvey, 1993). Desse modo, a NCP permitiria o surgimento de novas modalidades de exercício da cidadania (mais pontual, mais espontâneo), nas quais as pessoas se engajariam em torno de causas, apesar de essas modalidades continuarem sendo caracterizadas por um alto grau de civismo e de participação. Tal característica se traduz na oposição entre dois padrões de ação política: por um lado, o associativismo 
clássico, baseado na filiação dos indivíduos a ações coletivas e motivadas por objetivos permanentes - por exemplo, partidos, sindicatos e associações de moradores -, por outro, a mobilização sociopolítica, cujo traço principal é a ação contingencial dos participantes na arena política - como ilustram os novos movimentos sociais em torno dos direitos humanos difusos, a participação individual em manifestações, o boicote a produtos e a participação em fóruns pela internet. Ao mesmo tempo, a NCP tem relação com o surgimento de uma nova agenda política, fortemente associada a questões de gênero, étnico-raciais e ambientais. A análise da história brasileira sugere mais cautela nessa dicotomia entre mobilização e associativismo, possibilitando, por hipótese, a existência de vínculos não negligenciáveis entre esses dois processos, especialmente nas áreas urbanas não metropolitanas, apesar de podermos verificar, também no Brasil, a introdução de movimentos sociais em torno dos direitos difusos.

(vii) Existência dos mais fervorosos defensores da NCP nas sociedades menos hierárquicas e entre os indivíduos mais jovens, mais instruídos e os que vivem mais confortavelmente. Essas transformações tenderiam a ter mais força nas metrópoles e nos centros urbanos mais modernos - caracterizados por alcançarem elevados padrões de qualidade de vida - e atingiriam, de forma mais forte, os jovens. Tal tendência também pode ser observada no Brasil, mesmo que em menor escala de intensidade, se comparado aos países do Primeiro Mundo, devendo ainda ser destacada a possibilidade de esses valores da NCP estarem associados mais fortemente à vida metropolitana - o que podemos denominar de "efeito metrópole", considerando-se as históricas e fortes desigualdades culturais entre os mundos sociais agrário e urbano na sociedade brasileira.

De um lado é necessário considerar que estamos diante de transformações socioculturais e políticas que parecem ainda incipientes, quando se trata da sociedade brasileira, e fortemente circunscritas a alguns nichos altamente escolarizados; em geral situados nas grandes metrópoles. De outro, é preciso refletir sobre os limites e as potencialidades da matriz analítica da NCP em sua capacidade de explicação das mutações identificadas tanto nas sociedades desenvolvidas quanto na periferia do sistema. Isso deve ser feito levando-se em consideração não apenas os dados empíricos levantados na pesquisa realizada, mas também confrontando-os com outras abordagens explicativas das transformações da cultura política, em especial aquelas que considerem os impactos que os processos de diferenciação, segmentação e segregação 
socioespacial têm ocasionado na vida social, nos padrões de interação e na sociabilidade cívica das grandes cidades dos países emergentes.

\section{A COMPLEXA RELAÇÃO ENTRE ECONOMIA, CULTURA POLÍTICA E CIDADE: REFLEXÕES SOBRE O CASO BRASILEIRO}

A teoria democrática tradicionalmente refletiu sobre a questão do exercício da cidadania e de seu significado para a modernidade, seja na perspectiva clássica de Marshall (1967), seja nas versões posteriores (Dahl, 1997; Sartori, 1994; Putnam, 1996; O’Donnell, 1999; Taylor, 1992; Fraser e Honneth, 2003; entre outros). Dentre as abordagens contemporâneas podemos destacar o estudo de Putnam (1996), que, em seu conhecido trabalho sobre as diferenças de participação entre as comunidades do Norte e do Sul da Itália, busca superar o "dilema olsoniano" lançando mão do conceito de "capital social". Putnam parte da constatação de que os autores que considerarem a transgressão a atitude mais racional adotada pelos membros de um grupo social (Olson, 1999) subestimam a cooperação voluntária, frequente em muitas situações. Reconhece, entretanto, que, para a dinamização do comportamento cooperativo, é fundamental a existência de instituições formais capazes de reduzir os custos da fiscalização dos possíveis infratores e de fazer cumprir os acordos estabelecidos entre as partes. Baseado nessas premissas, Putnam busca entender as razões pelas quais certas instituições seriam capazes de superar a lógica olsoniana da ação coletiva, enquanto outras não o fazem. A resposta estaria, para o autor, no fato de as primeiras contarem, entre outros atributos, com limites claramente determinados, a participação dos interessados na definição das regras do jogo, a aplicação de sanções crescentes aos transgressores e a adoção de instrumentos pouco onerosos para o equacionamento dos conflitos.

A emergência, o curso da ação e os resultados alcançados por essas instituições dependeriam, fundamentalmente, do contexto social. É assim que, considerando os resultados de sua longa pesquisa, Putnam explica a enorme diferença observada entre o Sul e o Norte da Itália no enfrentamento dos dilemas da ação coletiva tomando como fundamento o conceito de "capital social". No Sul, mais pobre, onde o estoque de capital social disponível é escasso, seria observado o que ele chama de "vida coletiva atrofiada", pela incapacidade de haver cooperação em proveito mútuo. Longe de significar ignorância ou irracionalidade, a não cooperação seria produzida pela ausência de confiança 
mútua, o que levaria a maioria dos atores a assumir uma atitude oportunista. Em outras palavras, por falta de confiança em seus pares, os indivíduos adotam, quase sempre, uma opção "subótima", decorrente do cálculo de não cooperação do parceiro; ou seja, optam pela postura "dos males o menor". Já no Norte da Itália, a disponibilidade de capital social seria capaz de garantir o dinamismo econômico e um melhor desempenho governamental.

Putnam (1996) define o capital social como um bem público representado por atributos da estrutura social, tais como a confiança e a disponibilidade de normas e sistemas, que servem como garantia entre os atores, facilitando ações cooperativas. Assim como ocorre com o capital convencional, quanto maior a disponibilidade de capital social, maior a acumulação, que tem como componente básico a confiança cívica, fundada nas regras sociais de reciprocidade e nos sistemas de participação cívica. As regras sociais seriam disseminadas e mantidas por meio da socialização e do condicionamento, mas também da punição, resguardando a comunidade do oportunismo e fortalecendo a confiança social. A mais importante dessas regras, segundo Putnam, seria representada pela reciprocidade - a crença de que a confiança será retribuída -, seja específica, seja generalizada. Por sua vez, segundo Putnam, os sistemas de participação cívica constituem uma forma essencial de capital social e são representados por associações comunitárias, sindicatos, clubes desportivos, partidos políticos, cooperativas e outras formas associativas nas quais se observa intensa permuta interpessoal horizontal. Ou seja, essas instituições se assentam em uma relação simétrica entre agentes com igual poder, garantindo condições para que se promovam regras de reciprocidade, aumentando as possibilidades de informação sobre a confiabilidade dos indivíduos e também sobre os custos individuais das transgressões. Se, em vez de se restringirem a um grupo isolado, englobassem diferentes categorias sociais, os sistemas de participação horizontal seriam capazes de promover uma cooperação mais ampla (Azevedo e Mares Guia, 2001).

Inversamente, em sistemas de permuta vertical - no estudo de Putnam (1996), exemplificados pela Igreja Católica tradicional e pela máfia -, enfrentam-se dificuldades na promoção e na garantia da confiança e da cooperação. De início, os fluxos de informação tornam-se menos confiáveis, e as penalidades que garantiriam a reciprocidade muito raramente seriam aplicadas ao superior pelo subalterno. Prevalecem a desconfiança mútua, a transgressão, a exploração, entre outros atribu- 
tos. É nesse campo, caracterizado pela desigualdade das obrigações e pela dependência entre as partes, que se estabelecem relações clientelistas marcadas pelo intercâmbio vertical. Segundo Putnam (ibidem:184), nesse tipo de relação, "é mais provável haver oportunismo por parte do patrono (exploração) do que por parte do cliente (omissão)".

O autor conclui que tanto a confiança/reciprocidade quanto a dependência/exploração seriam capazes de produzir equilíbrios estáveis em uma sociedade, garantindo sua unidade. Seriam observadas, entretanto, acentuadas diferenças na eficiência e nos resultados de seu desempenho institucional. Os dilemas da ação coletiva seriam enfrentados com mais chances de sucesso por meio dos sistemas horizontais de participação cívica, favorecendo o bom desempenho governamental. Ou seja, haveria uma forte correlação positiva entre associações cívicas e instituições públicas eficazes: quanto mais cívico o contexto, melhor o governo. Nessas sociedades, os valores democráticos de autoridades e de cidadãos, aliados à infraestrutura social já existente nas comunidades cívicas, contribuiriam para o bom desempenho do governo ${ }^{4}$.

Assim, os cidadãos de uma comunidade cívica demandam um bom governo e atuam nessa direção; reivindicam serviços e equipamentos públicos e são capazes de agir coletivamente nesse sentido. Já em regiões menos cívicas, onde o capital social é escasso ou nulo, sem regras e sem sistemas de participação cívica, o equilíbrio social seria caracterizado pelo "desertar sempre". Em um contexto de ilegalidade previsível em que a desconfiança e a corrupção são consideradas normais - e de escassa participação em associações, os cidadãos acabariam por assumir "papel de suplicantes cínicos e alienados".

Uma leitura ortodoxa de Putnam poderia nos levar a pensar que as sociedades com baixo grau de capital social - como a brasileira e a de outros países emergentes - estariam fadadas ao fracasso no enfrentamento dos dilemas de ação coletiva por meio de mecanismos democráticos. Cabe ressaltar que trabalhos recentes têm matizado interpretações culturalistas que superestimam a importância da confiança interpessoal como elemento central para explicar políticas e contextos democráticos. Nesse sentido, Feres Júnior e Eisenberg (2006) fazem uma crítica ao conceito de confiança interpessoal utilizado pelas abordagens culturalistas como capaz de explicar o surgimento de ambientes democráticos. Para os autores, tal formulação desconsideraria o papel que as 
instituições que processam conflitos (direito, polícia etc.) têm na mediação de relações interpessoais em todas as sociedades modernas (ibidem).

Com base na análise do trabalho de Inglehart (1999) - que se inspirou em Putnam e em outros autores culturalistas -, Feres Júnior e Eisenberg (1996) buscam mostrar que, em virtude de sua fragilidade analítica, o conceito de confiança interpessoal é ineficaz como ferramenta empírica. Nesse sentido, respostas obtidas nas pesquisas de opinião pública referentes ao conceito de confiança e, ainda, eventuais correlações entre "confiança interpessoal e estabilidade democrática" devem ser vistas com cautela. Nas palavras dos autores, "não há, a princípio, nenhuma razão para crer que este tipo de confiança não possa existir, ou mesmo vicejar, em ambientes de degradação da cultura democrática, segregação, autoritarismo, ou mesmo em sociedades fortemente hierarquizadas" (ibidem:458). Em contraposição a essa perspectiva, Feres Júnior e Eisenberg defendem a "confiança em instituições" como ferramenta de aferição de como os regimes políticos reais se aproximariam ou se afastariam do modelo democrático normativo, sugerido por eles, baseado no tripé: reconhecimento do sujeito, justiça distributiva e possibilidade de rediscussão das normas (discussão, deliberação e revisão) mediada por procedimento democrático. Dessa maneira, conforme observado por Levi (1996:83), as instituições resolvem problemas da ação coletiva trazendo à tona contribuições de indivíduos que, por sua vez, só conseguem realizar seus desígnios porque há alguém (ou algumas pessoas) que tem (ou têm) o poder de coordenar, ou coagir, ou mobilizar um grupo de pessoas para agir conjuntamente.

O debate contemporâneo não se restringe, porém, à dimensão do capital social e da confiança como elementos que possibilitam entender os diferentes padrões de participação cívica. Enquanto as obras clássicas difundiram a percepção de que a extensão da cidadania era um processo histórico, desde os direitos civis e políticos até os de caráter social, as recentes interpretações, além de incorporarem a dimensão dos chamados direitos difusos (meio ambiente, multiculturalismo, biodiversidade, orientação sexual, entre outros), convergem na constatação da existência de um crescente déficit de participação política e de menor identificação da população com as instituições democráticas, pelo menos desde a década de 1990. Tal processo seria observado tanto nas democracias consolidadas do Primeiro Mundo quanto nas chamadas "novas democracias" dos países emergentes (O’Donnell, 1999). 
Os autores que abordam a questão da cidadania contemporânea identificam, em maior ou menor grau, as mudanças na cultura política e nas modalidades de ação coletiva na pós-modernidade que, em nosso entender, não pode ser compreendida fora do contexto atual da globalização. Como afirma Harvey (2004:88), podemos conceber a globalização contemporânea como "um processo de produção de desenvolvimento temporal e geográfico desigual" na atual fase de desenvolvimento do capitalismo.

Tomando como referência o próprio Harvey, mas também diversos outros autores (ver, por exemplo, Castel, 1998; Bauman, 1999; Castells, 1985; Clark e Inglehart, 2007; Harvey, 1993; Hobsbawm, 1995), podemos condensar os principais processos relacionados ao fenômeno da globalização: (i) ela decorreria de dois fatores: da revolução tecnológica e da liberalização financeira dos mercados de capitais dos países industrializados; (ii) traria tanto uma maior homogeneização do consumo e da produção de bens de baixa e média tecnologia quanto uma maior individualização e diversificação de produtos "nobres" - relacionados ao lazer e ao bem-estar individual -, proporcionadas pelas profundas mudanças tecnológicas, pelas inovações dos produtos e pela adoção de modos mais flexíveis de acumulação do capital; (iii) a redução no custo e no tempo das comunicações e dos transportes de mercadorias e pessoas causaria fortes impactos sobre as formas hegemônicas pelas quais experimentamos a sensação de compressão do tempo e do espaço, fragmentando as conexões entre atores e instituições, e tornando a sociabilidade fragilizada e destituída de valores e crenças duradouras; (iv) a ascensão de novas formas culturais de representação associadas à pós-modernidade estaria relacionada à condição histórico-geográfica específica da longa trajetória do capitalismo; (v) o processo de crescimento, apogeu e crise do Welfare State e da sociedade assalariada, bem como dos sindicatos, acarretaria o enfraquecimento do modo de integração social até então vigente; (vi) a desregulamentação financeira geraria o enfraquecimento do Estado-Nação em sua capacidade de promover a articulação entre mercado, território e sociedade; (vii) a maior visibilidade social das questões étnicas e multiculturais como o epicentro da conflitualidade social em relação aos conflitos centrados nas classes sociais; e (viii) o fortalecimento do individualismo como valor ético, sem significar a diminuição, pelo menos na retórica, da questão social.

Nesse novo cenário internacional, algumas características do panorama político global se destacam. A mais evidente delas é o enfraqueci- 
mento relativo do Estado nacional, instituição central da política desde a "Era das Revoluções", em virtude tanto de seu monopólio do poder público e da lei quanto do fato de constituir o campo efetivo de ação política para a maioria dos atores (Hobsbawm, 1995).

Mesmo ocorrendo interpretações divergentes sobre a caracterização da crise do Estado, a maioria dos estudiosos concorda que as sociedades contemporâneas passam por um período de rápida reestruturação. Pode-se dizer que os processos de transformação econômica em curso nas últimas duas décadas romperam as amarras regulatórias tradicionais do Estado (Touraine, 1995). Assim, mesmo em contextos e em setores em que não ocorreu uma desregulação oficial ou formal da economia, na prática, parte considerável do quadro legal tornou-se superada. Em suma, um dos desafios no início deste século seria a formação de um novo marco de regulação, por parte do Estado, que desse conta da profunda complexidade e das idiossincrasias das sociedades contemporâneas. Lembram alguns autores que a ampliação da esfera pública e o fortalecimento progressivo do poder de regulação do Estado ao longo do século XX (leis antitrust, legislação trabalhista, previdência, seguridade social etc.) ocorreram, fundamentalmente, para se contrapor aos efeitos perversos do "mercado livre" (Castel, 1998)

Atualmente, embora variando em função das características locais, há uma tendência de diminuição da participação direta do Estado como produtor direto de bens e serviços, e de aumento das atividades referentes ao incentivo e à orientação dos investimentos do setor privado em áreas consideradas, pelo setor público, estratégicas ou prioritárias, bem como o incremento das atividades de regulação e de parcerias com diferentes atores da sociedade civil (Osborne e Gaebler, 1992). Essa tendência não significa que o Estado deixou de ser um instrumento político relevante - como poderia levar a crer uma interpretação ingênua do processo de globalização -, mas que é necessário refletir sobre seus novos papéis nos contextos do desenvolvimento capitalista contemporâneo e das mudanças culturais associadas à condição pósmoderna, bem como sobre seus impactos nos arranjos institucionais liberais e na dinâmica democrática.

As atuais características do sistema financeiro internacional reduzem fortemente as margens de manobra econômica dos governos nacionais, especialmente na periferia do sistema. Qualquer intento de realizar medidas heterodoxas implica, imediatamente, uma fuga de capi- 
tais, o que equivale, nas palavras de Reis (2000), a um "golpe de mercado". Como bem lembra Boschi (2004), nessa conjuntura, os políticos das democracias emergentes, como a brasileira, são levados a apresentar retóricas e práticas aparentemente paradoxais, pois, nos períodos pré-eleitorais, enfatizam a necessidade de criação de empregos, de altas taxas de crescimento econômico e a ampliação das políticas sociais para terem possibilidade de ser eleitos. Passadas as eleições, deparam-se com a necessidade de adotar - com maior ou menor flexibilidade - políticas ortodoxas de contenção da inflação, equilíbrio macroeconômico, juros elevados etc., sob pena de terem que enfrentar crises de grandes proporções (ibidem).

Tendo em vista esse quadro, torna-se necessário refletir sobre os impactos dessas transformações econômicas e sociais na cultura política. Estamos nos referindo à cultura política entendida como "a generalização de um conjunto de valores, orientações e atitudes políticas entre os diferentes segmentos" sociais e que "resulta tanto dos processos de socialização, como da experiência política concreta dos membros de uma comunidade política" (Moisés, 1992:7). Segundo Moisés, é difícil determinar as causas últimas geradoras da cultura política; ou seja, se são as instituições que geram a cultura política ou o inverso. Nesse sentido, concordamos com o autor que "as decisões tomadas pelos atores relevantes sobre a estrutura política sofrem o impacto contextual; isto é, da natureza das disputas políticas [e econômicas], das concepções que os atores têm sobre ela e dos padrões de comportamento político vigentes ou herdados do passado" (idem, ibidem:19). Por isso, seria mais apropriado falarmos de uma mútua influência entre os contextos social, econômico e institucional e os valores e as crenças políticas.

Nessa perspectiva, caberia indagar sobre as consequências das transformações relacionadas à globalização contemporânea no processo de modernização dos países em desenvolvimento e seus impactos na cultura política, refletindo, ao mesmo tempo, como a cultura política preexistente incide sobre esse processo de transformação. A nosso ver, a permanência e a reprodução de uma cultura no longo prazo - por exemplo, a manutenção da cultura patrimonialista e patriarcal - só são possíveis quando essa cultura se adapta ou, no mínimo, não entra em contradição com os interesses hegemônicos e com a correlação de forças existentes em uma dada sociedade. No curto prazo, em momentos de grandes transformações econômicas e sociais, é razoável um des- 
compasso maior entre essas dimensões culturais e as condições econômicas e institucionais ${ }^{6}$.

As dificuldades de mudanças políticas decorrem, normalmente, da resistência de atores que temem perder privilégios ou vantagens relativas. Poderíamos dizer que mudanças na cultura política são de tal modo marcadas por comportamentos de atores hegemônicos que, mesmo quando, do ponto de vista da retórica oficial e da legislação legal, se logra avançar para relações mais simétricas, isso não se reflete da mesma forma nas interações sociais. A farta bibliografia sobre relações de gênero e entre etnias são exemplos marcantes que afetam - ainda que em grau diferenciado - tanto a civilização ocidental como diversas formações culturais do Oriente, atingindo países desenvolvidos e emergentes.

Cabe ressaltar que, pelo menos no caso ocidental, há uma clara correlação entre modernização capitalista e diminuição das desigualdades culturais; ou seja, as desigualdades que têm por base origem, credo religioso, gênero e cor da pele. Em outras palavras, o desenvolvimento capitalista tem um caráter progressista, pois, ao definir o mercado lato sensu como o único balizador das desigualdades, tende a diminuir as diferenças de ordem adscritivas.

Assim, no caso do Brasil, cremos que é necessário levar em consideração a questão das desigualdades sociais como um elemento-chave que marca nossa modernidade e nossa cultura política. Entre os autores contemporâneos que analisam a questão da desigualdade nos países periféricos, buscando fornecer subsídios para explicar as fortes tensões entre cultura e economia, chama a atenção - pela autenticidade da interpretação e por instigar o debate em pauta - Jessé de Souza (ver Souza, 2000; 2003). Esse autor, questionando as interpretações clássicas de abordagens baseadas no paradigma do dualismo cultural (personalismos, herança patrimonialista, homem cordial, resíduos prémodernos, hibridismos, entre outros), defende uma nova leitura que possibilite compreender o Brasil como uma economia de mercado extremamente complexa. Segundo Souza (2003), o que tornaria possível legitimar a desigualdade social tanto no Brasil como em qualquer economia capitalista adiantada seria a ideologia do desempenho que se encontra arraigada de forma pré-reflexiva nas sociedades de mercado. Nas palavras do autor, todo indivíduo, para ter a possibilidade de ser 
incluído em uma determinada sociedade de mercado, necessita possuir

um conjunto de predisposições psicossociais refletindo, na esfera da personalidade, a presença da economia emocional e das precondições cognitivas para um desempenho adequado ao atendimento das demandas (variáveis no tempo e no espaço) do papel de produtor, com reflexos diretos no papel do cidadão, sob condições capitalistas modernas (ibidem:170).

O autor, inspirado em Bourdieu, denomina esse conjunto de atributos "habitus primário", sendo a internalização deles, aliada à disciplina do trabalho, fundamental para se alcançar o princípio básico do consenso do cidadão nas modernas sociedades capitalistas. A inexistência do desempenho compatível e da disciplina no trabalho levaria a um habitus marcado pela precariedade, designado por Souza como "habitus precário".

O que diferiria o Brasil e as demais emergentes economias de mercado dos países desenvolvidos seria que o percentual dos casos de "habitus precário" seria muito elevado. Para Souza, no Brasil estamos diante

de uma gigantesca "ralé" de inadaptados às demandas da vida produtiva e social modernas, constituindo-se em uma legião de "imprestáveis", no sentido sóbrio e objetivo do termo, com óbvias consequências, tanto existenciais, na condenação de dezenas de milhões a uma vida trágica sob o ponto de vista material e espiritual, quanto sociopolíticas, como a endêmica insegurança pública e a marginalização política e econômica desses setores (ibidem:184).

Debatendo com DaMatta, para quem a aplicação das regras e das leis em situações sociais assimétricas apresenta por parte dos atores envolvidos uma intencionalidade favorável àquele que possui contatos e relações privilegiadas no aparelho de $\operatorname{Estado}^{7}$, Souza entende que esse processo se daria sem nenhum acordo consciente. O que existiria seriam "acordos mudos e subliminares, mas, por isso mesmo, tanto mais eficazes que articulam, como que por meio de fios invisíveis, solidariedades e preconceitos profundos e invisíveis" (ibidem:175). Segundo o autor, esses consensos sociais pré-reflexivos se dariam pela forte distinção não consciente entre os "europeus" e a "ralé".

Souza ressalta ainda que, desde meados do século XIX, a questão do desempenho tem sido valorizada e não pode ser considerada "coisa 
para inglês ver". Para o autor, relacionamentos privilegiados ocorrem em todas as economias de mercado, o mesmo acontecendo com a corrupção e a promiscuidade entre atores políticos. Em nossa interpretação, entretanto, Souza não consegue demonstrar que esses fatos tenham a mesma dimensão em países desenvolvidos e periféricos.

Ainda que o universalismo de procedimentos no Brasil - predominante nos países democráticos desenvolvidos - venha aumentando paulatinamente sua importância ao longo das últimas décadas, está longe de constituir a gramática hegemônica de nosso dia a dia. Nesse sentido mesmo aceitando-se a interpretação de Souza no plano mais estrutural -, para o caso brasileiro, a perspectiva damattiana não poderia ser totalmente descartada. Apesar do avanço paulatino nos serviços públicos de procedimentos universalistas, como a utilização de senhas para atendimentos em hospitais, escolas públicas, delegacias de polícia, bancos, companhias de aviação etc., continuam a funcionar paralelamente - ainda que de forma discreta - atendimentos preferenciais marcados por relações personalizadas. Esse é um mecanismo tão arraigado, legitimado e generalizado no país que corta transversalmente toda a estrutura organizacional das empresas de prestação de serviços, pois tanto os dirigentes como os funcionários dos diversos escalões hierárquicos, em suas respectivas áreas de competência, lançam mão desses procedimentos para favorecer parentes, amigos e até mesmo pessoas indicadas por conhecidos.

Isso é ainda mais óbvio nas regiões menos desenvolvidas do país. Como lembra Nunes (1997), no Brasil se usam diferentes gramáticas políticas, dependendo do momento e do local: universalismo de procedimentos, clientelismo, corporativismo e insulamento burocrático. No caso brasileiro, é bastante comum a utilização dessas diferentes abordagens de forma cruzada; por exemplo, clientelismo, mas respeitando-se um teto meritocrático básico.

A extrema desigualdade de nossa estrutura social termina por criar "submundos sociais" tão distintos que apresentam, sob alguns aspectos, pouca porosidade entre si (Reis, 1988). Conceitualmente, quando buscamos discutir temas como tratamento médico, salário, lazer, moradia, transporte, associativismo, mobilização e cidadania, as diferenças e as percepções dessas e de outras questões são tão grandes, entre os diversos setores sociais, que exigiriam análises diferenciadas ou, pelo menos, matizadas.

Nesse sentido, é fundamental destacar a especificidade da dimensão metropolitana para a compreensão da sociedade brasileira. O Brasil 
possui vinte e oito regiões metropolitanas, sendo que as nove primeiras foram institucionalizadas na década de 1970, durante o regime militar, e as demais, nos anos 1990, por iniciativa de governos estaduais. Essas regiões metropolitanas reúnem cerca de 65 milhões de pessoas, $\mathrm{o}$ que corresponde a $47 \%$ da população urbana e a $38 \%$ dos habitantes do país. As grandes metrópoles brasileiras se caracterizam não só por concentrarem a maior parte da riqueza nacional como também por possuírem expressivos focos de pobreza e de exclusão social: encontram-se, nas regiões metropolitanas, $48 \%$ dos pobres, $90 \%$ dos domicílios localizados em favelas e, simultaneamente, $69 \%$ do Produto Interno Bruto (PIB) brasileiro (Davidovich, 2001). A partir dos anos 1990, o processo de metropolização avança e se diversifica no território nacional. Temos regiões metropolitanas com diferentes dinâmicas econômicas e demográficas, desde megacidades, como São Paulo, reunindo mais de 19 milhões de habitantes, até pequenas aglomerações urbanas institucionalizadas como metropolitanas. Muitas dessas metrópoles e aglomerações urbanas se articulam, configurando novos arranjos espaciais, com redobrada importância nos planos econômico e social, e também redobrada complexidade política e cultural. Ao lado das evidências do aumento da importância demográfica e econômica, as metrópoles brasileiras estão concentrando, hoje, a problemática social, cujo lado mais evidente e dramático é a exacerbação da violência, com seus impactos sobre as formas de exercício da cidadania. O aumento da violência nas metrópoles guarda fortes relações com os processos de segmentação socioterritorial em curso, que separam as classes e os grupos sociais em espaços de abundância e de integração virtuosa e em espaços de concentração da população vivendo simultâneos processos de exclusão social (Ribeiro e Santos Junior, 2007).

Tendo em vista as características de nossa cultura política, marcada por diferentes segmentações sociais e espaciais, torna-se necessário refletir sobre os impactos das transformações relacionadas à globalização contemporânea - anteriormente analisada - em nossa dinâmica social e política. Uma análise do panorama da cultura política brasileira, com foco em alguns dos principais centros urbanos do país, pode contribuir nesse sentido.

\section{CULTURA POLÍTICA E EXERCÍCIO DA CIDADANIA NO BRASIL}

Tomando como referência a pesquisa realizada pelo Observatório das Metrópoles, em parceria com outras instituições nacionais e internacionais, podemos cotejar o debate anterior em torno da cultura política 
- nas dimensões valorativa, cognitiva e afetiva - com algumas informações empíricas sobre o Brasil, buscando entender e explicar o exercício da cidadania e traçar uma radiografia comparativa da motivação dos brasileiros $^{8}$ na ação política. Nessa análise, procuramos, de um lado, comparar o Brasil com outros seis países onde a mesma pesquisa foi realizada (Canadá, Estados Unidos, França, Suécia, Espanha e Portugal); de outro, ressaltar a cultura política dos principais centros urbanos metropolitanos do país, comparando os dados nacionais com os de outras sete cidades selecionadas (São Paulo, Porto Alegre, Rio de Janeiro, Belo Horizonte, Recife, Natal e Goiânia), a fim de identificar diferenças que possam ser relacionadas à dinâmica metropolitana. Para tanto, privilegiamos os seguintes indicadores: a) associativismo e mobilização; b) predisposição para a ação política; c) percepção sobre deveres e direitos relativos ao exercício da cidadania.

\section{a) Associativismo e mobilização}

A última pesquisa realizada sobre o tema do associativismo no Brasil apontava que $27 \%$ das pessoas adultas com 18 anos ou mais, moradoras das regiões metropolitanas, estavam filiadas a algum tipo de associação (IBGE, 1997), fosse esta de caráter religioso, esportivo, cultural, reivindicativo, corporativo, social ou político. Assim, à primeira vista, pareceria possível afirmar que prevalece, no Brasil, um baixo grau de associativismo. Entretanto, tomando como referência os dados mais recentes de nossa pesquisa, quando comparamos a intensidade da participação e do pertencimento a associações no Brasil com a de diversos países desenvolvidos onde pesquisa similar foi realizada, constatamos que, apesar de estarmos muito abaixo dos índices dos países anglo-saxônios e escandinavos (Estados Unidos, Canadá, Suécia), situamo-nos em posição intermediária se comparados a países latino-europeus; estamos acima de Portugal e Espanha e abaixo da França (Tabela 1).

No caso brasileiro, chama a atenção o fato de a participação e o associativismo religioso serem relativamente mais importantes, alcançando índices que superam em mais do que o dobro aqueles alcançados pelas demais formas associativas. É interessante notar ainda que mesmo os países com forte associativismo religioso - inclusive superiores ao brasileiro, como Estados Unidos, Canadá e Suécia - não apresentam grandes diferenças entre esse tipo de associativismo e os demais, especialmente aqueles vinculados aos grupos desportivos e culturais e aos sindicatos e associações profissionais, tal como verificado no Brasil. 
Sérgio de Azevedo, Orlando Alves dos Santos Junior e Luiz César de Queiroz Ribeiro

Tabela 1

Índice de Intensidade de Associativismo por Tipo de Organização (médias)

Brasil e Países Selecionados - 2006

\begin{tabular}{l|c|c|c|c|c|c|c}
\hline $\begin{array}{l}\text { Formas de } \\
\text { Associativismo }\end{array}$ & Brasil & Canadá & Suécia & $\begin{array}{c}\text { Estados } \\
\text { Unidos }\end{array}$ & França & Espanha & Portugal \\
\hline $\begin{array}{l}\text { (i) Partido político } \\
\begin{array}{l}\text { (ii) Sindicato, grêmio } \\
\text { ou associação } \\
\text { profissional }\end{array}\end{array}$ & 0,23 & 0,43 & 0,37 & 1,03 & 0,19 & 0,20 & 0,17 \\
$\begin{array}{l}\text { (iii) Igreja ou } \\
\text { organismo } \\
\text { religioso }\end{array}$ & 0,46 & 1,25 & 1,59 & 0,73 & 0,67 & 0,46 & 0,40 \\
$\begin{array}{l}\text { (iv) Grupo desportivo, } \\
\text { recreativo ou } \\
\text { cultural }\end{array}$ & 1,18 & 1,61 & 1,39 & 1,87 & 0,60 & 0,51 & 0,83 \\
$\begin{array}{l}\text { (v) Outra associação } \\
\text { voluntária }\end{array}$ & 0,43 & 1,64 & 1,60 & 1,13 & 1,49 & 0,81 & 0,48 \\
\hline $\begin{array}{l}\text { Média } \\
\text { N } \quad 0,27\end{array}$ & 1,26 & 0,79 & 0,96 & 1,05 & 0,47 & 0,31 \\
\hline
\end{tabular}

Fonte: Pesquisa Observatório das Metrópoles, IUPERJ, ICS-UL, ISRP (2006).

Escala: (3) participa ativamente; (2) pertence, mas não participa ativamente; (1) já pertenceu; (0) nunca pertenceu ${ }^{9}$.

Em geral, assim como observado nos demais países onde essa pesquisa foi aplicada, o Brasil apresenta níveis de mobilização sociopolítica ${ }^{10}$ superiores aos níveis de participação em organizações associativas (Tabela 2). No entanto, deve-se destacar que - diferentemente dos níveis de associativismo, no qual mantemos uma posição intermediária - o grau de mobilização sociopolítica no Brasil é inferior aos de todos os demais países considerados, até mesmo quando se observam os diferentes tipos de ação examinados, com exceção da participação em comícios (em que superamos, levemente, Suécia, Espanha e Portugal) e em fóruns pela internet (quanto a isso, os brasileiros aparecem um pouco mais engajados do que os franceses e espanhóis).

Analisando esses diferentes tipos de mobilização sociopolítica, podemos constatar que as duas modalidades com maior participação dos brasileiros são a assinatura de abaixo-assinados e a participação em comícios. No primeiro caso, caracteriza-se por um baixo custo de engajamento, não se exigindo mais do que uma simples assinatura, sem maiores consequências. Já no que se refere aos comícios, é preciso levar em consideração os incentivos seletivos tradicionalmente utilizados 
Tabela 2

Índice de Mobilização Sociopolítica (médias)

Brasil e Países Selecionados - 2006

\begin{tabular}{|c|c|c|c|c|c|c|c|}
\hline $\begin{array}{l}\text { Modalidade de Ação } \\
\text { Sociopolítica }\end{array}$ & Brasil & Canadá & $\begin{array}{l}\text { Estados } \\
\text { Unidos }\end{array}$ & França & Suécia & Espanha & Portugal \\
\hline $\begin{array}{l}\text { (i) Assinar um abai- } \\
\text { xo-assinado }\end{array}$ & 1,15 & 2,21 & 1,92 & 2,05 & 2,13 & 1,44 & 1,15 \\
\hline $\begin{array}{l}\text { (ii) Boicotar produ- } \\
\text { tos por questões } \\
\text { políticas, éticas e } \\
\text { ambientais }\end{array}$ & 0,51 & 1,83 & 1,36 & 1,54 & 1,76 & 0,97 & 1,01 \\
\hline $\begin{array}{l}\text { (iii) Participar em } \\
\text { uma manifesta- } \\
\text { ção }\end{array}$ & 0,76 & 1,07 & 0,86 & 1,50 & 1,07 & 1,61 & 0,96 \\
\hline $\begin{array}{l}\text { (iv) Participar em } \\
\text { um comício }\end{array}$ & 1,07 & 1,20 & 1,17 & 1,12 & 1,04 & 1,00 & 0,86 \\
\hline $\begin{array}{l}\text { (v) Contactar político } \\
\text { ou alto funcioná- } \\
\text { rio do Estado }\end{array}$ & 0,60 & 1,46 & 1,47 & 0,89 & 1,00 & 0,74 & 0,77 \\
\hline $\begin{array}{l}\text { (vi) Dar dinheiro ou } \\
\text { recolher fundo } \\
\text { para causas pú- } \\
\text { blicas }\end{array}$ & 0,61 & 1,64 & 1,63 & 1,38 & 1,43 & 0,97 & 1,63 \\
\hline $\begin{array}{l}\text { (vii) Contactar ou } \\
\text { aparecer na mí- } \\
\text { dia }\end{array}$ & 0,45 & 0,92 & 0,81 & 0,64 & 0,68 & 0,56 & 0,69 \\
\hline $\begin{array}{l}\text { (viii) Participar em } \\
\text { fóruns pela inter- } \\
\text { net }\end{array}$ & 0,44 & 0,58 & 0,52 & 0,42 & 0,44 & 0,38 & 0,63 \\
\hline Média & 0,70 & 1,36 & 1,22 & 1,22 & 1,19 & 0,96 & 0,97 \\
\hline $\mathbf{N}$ & 2.000 & 1.068 & 1.485 & 1.421 & 1.295 & 2.481 & 1.602 \\
\hline
\end{tabular}

Fonte: Pesquisa Observatório das Metrópoles, IUPERJ, ICS-UL, ISRP (2006).

Escala: (3) fez no último ano; (2) fez em anos anteriores; (1) não fez, mas poderia ter feito; (0) nunca o faria $^{11}$.

para a mobilização popular por meio de "showmícios" com artistas conhecidos, especialmente nas periferias das grandes cidades e no interior do país.

No que diz respeito às modalidades de menor engajamento dos brasileiros, aparecem a participação em fóruns pela internet e o contato com a mídia. No entanto, há que se destacar que, apesar de baixo, o grau de envolvimento sociopolítico pela internet segue o padrão médio alcançado pelos demais países. Por outro lado, a maior diferença relativa encontrada nessa comparação se refere ao boicote de produtos por ques- 
tões éticas, políticas e ambientais, em que praticamente todos os países apresentam um índice de engajamento nesse quesito duas ou mais vezes maior do que o do Brasil.

Vale lembrar que a abordagem da NCP sustenta que estaria ocorrendo uma mudança nos padrões de ação política, com a passagem de formas mais tradicionais (vinculadas aos partidos e sindicatos) para outras mais flexíveis, em que os vínculos seriam mais pontuais e ligados a diferentes causas políticas (em especial, relacionadas à agenda ambiental e aos valores pós-materialistas). Na pesquisa em questão, há indícios de que, apesar de crescentes, as práticas que caracterizariam a presença da NCP seriam ainda incipientes entre nós, persistindo a força relativa das organizações associativas tradicionais e suas respectivas modalidades de mobilização (abaixo-assinado, manifestações, comícios, greves etc.).

Nesse sentido, talvez seja interessante refletir sobre a relação entre associativismo e mobilização no Brasil, onde os processos de mobilização sociopolíticos parecem engajar pessoas com algum vínculo às organizações associativas existentes (Tabela 3), se bem que existam muitas diferenças quando consideramos o tipo de associativismo e a modalidade de mobilização. $\mathrm{O}$ associativismo religioso, que mobiliza o maior percentual de pessoas no país, é o que menos engaja, proporcionalmente, na participação em ações de mobilização sociopolítica, qualquer que seja a modalidade considerada; o associativismo partidário sobressai na participação em comícios ou em reuniões políticas; o associativismo sindical, na participação em greves; o associativismo cultural, na participação em manifestações; e as outras associações voluntárias (que reúnem as associações de moradores e as ONGs), no boicote aos produtos, nos abaixo-assinados, na doação de dinheiro para causas públicas e nos fóruns de discussão pela internet.

Segundo a literatura existente, quanto maiores os níveis de escolaridade, mais elevados são os percentuais de associação civil (Santos, 1993; Ribeiro e Santos Junior, 1996). Em um contexto social marcado por grandes desigualdades educacionais, como no caso brasileiro, e levando-se em conta nosso nível associativo, tal fato se apresenta como um fator de risco de reprodução das desigualdades sociais, tendo em vista que a dinâmica de participação cívica nas cidades ainda é restrita a um pequeno segmento social que convive com a apatia política de amplas parcelas da população. Na pesquisa aqui realizada, essa assertiva é 
Mudanças e Permanências na Cultura Política das Metrópoles Brasileiras

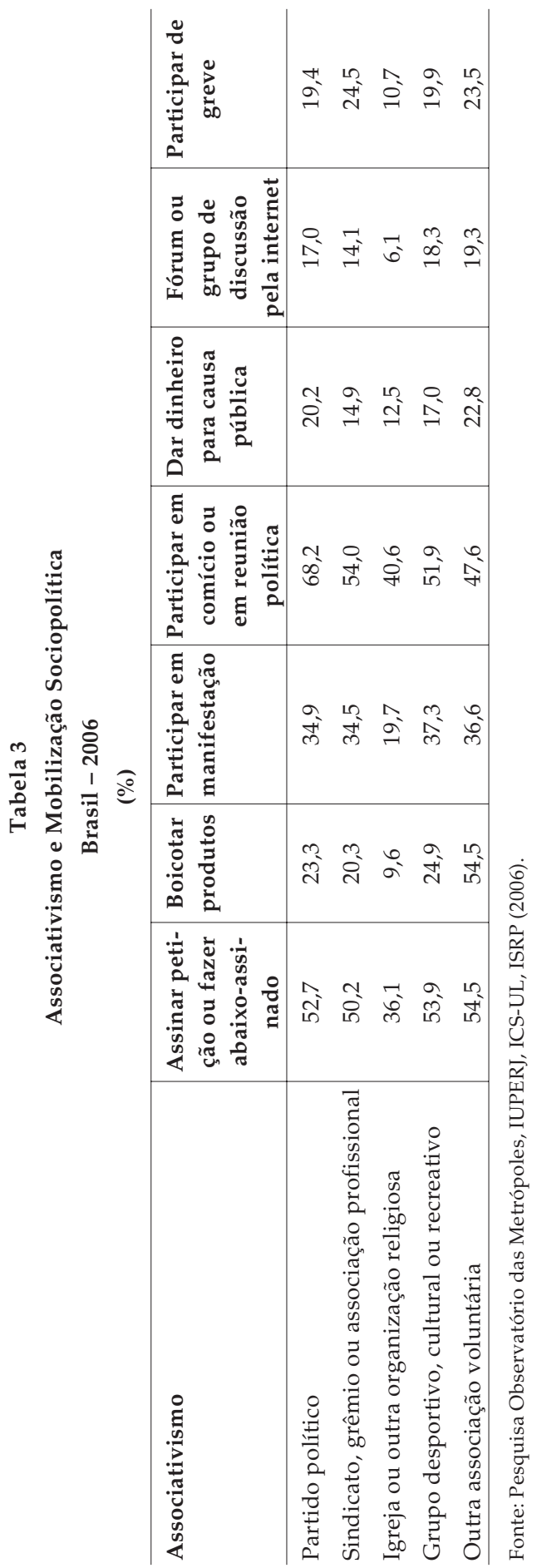


complementada pela relação entre o nível educacional e a mobilização política: aqueles que possuem nível superior apresentam um grau de engajamento muito maior do que os que têm baixa escolaridade, sobretudo no que se refere às práticas associadas às novas formas de ação sociopolítica, tais como participar de fórum pela internet, boicotar produtos e contactar ou aparecer na mídia (Tabela 4).

Além disso, é interessante notar que os padrões predominantes de mobilização sociopolítica se alteram de acordo com as faixas de escolaridade consideradas. Assim, até a quarta série fundamental (atual quinto ano) predomina a participação em comícios, enquanto os fóruns pela internet são o que menos mobiliza esse segmento. A partir dessa faixa de escolaridade, vigora com mais força a participação em abaixo-assinados. É interessante destacar o crescimento em importância da participação em fóruns pela internet, cinco vezes mais forte como fator de engajamento no segmento superior em relação ao setor de menor nível educacional, além de se constituir na quarta modalidade mais importante para esse primeiro grupo.

Buscando identificar mudanças na cultura política das metrópoles brasileiras, busca-se, agora, estabelecer a comparação entre as diferentes cidades onde a pesquisa foi realizada ${ }^{12}$. Nessa perspectiva, os dados indicam que São Paulo e Porto Alegre se diferenciam do conjunto das demais cidades por alcançarem índices bem superiores à média nacional, tanto no que se refere à intensidade de associativismo como no que se refere à intensidade de mobilização sociopolítica (Tabela 5). As demais cidades se situam mais próximas da média nacional, com exceção de Belo Horizonte, que, nos dois casos, atingiu índices bem inferiores.

\section{b) Predisposição para a ação sociopolítica}

Os níveis de associativismo e de mobilização sociopolítica certamente estão relacionados às percepções em torno do sistema político, mas os comportamentos sociopolíticos são resultado de processos de aprendizagem, implicando, segundo o contexto social e as opções pessoais, atitudes políticas ativas ou passivas. Entendendo que os comportamentos sociopolíticos são passíveis de aprendizado, podemos dizer que o comportamento de uma pessoa "como sujeito ativo ou como indivíduo politicamente passivo tem muito a ver com a própria trajetória" (Saraí Schmidt apud Baquero e Baquero, 2007), o que põe em xeque o processo 
Mudanças e Permanências na Cultura Política das Metrópoles Brasileiras

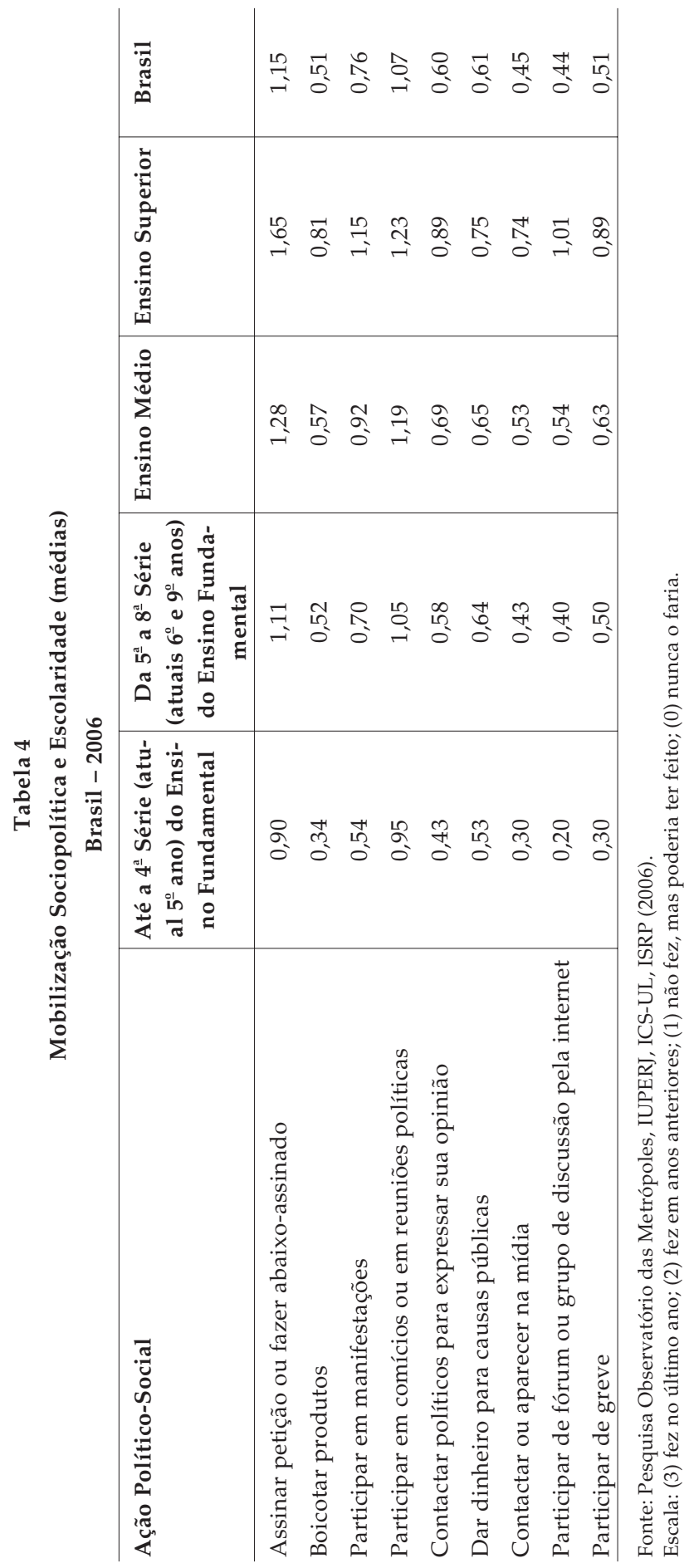


Sérgio de Azevedo, Orlando Alves dos Santos Junior e Luiz César de Queiroz Ribeiro

Tabela 5

Associativismo e Ação Política e Social (médias)

Brasil e Cidades Selecionadas - 2006-2008

\begin{tabular}{l|c|c|c|c}
\hline \multirow{2}{*}{ Cidade } & \multicolumn{2}{|c|}{ Associativismo } & \multicolumn{2}{c}{ Mobilização } \\
\cline { 2 - 5 } & Média & $\mathbf{N}$ & Média & $\mathbf{N}$ \\
\hline São Paulo & $0,66 \mathrm{~d}$ & 384 & $0,91 \mathrm{c}$ & 384 \\
Porto Alegre & $0,60 \mathrm{c}, \mathrm{d}$ & 383 & $0,84 \mathrm{c}$ & 383 \\
Rio de Janeiro & $0,51 \mathrm{~b}$ & 499 & $0,69 \mathrm{~b}$ & 498 \\
Belo Horizonte & $0,37 \mathrm{a}$ & 383 & $0,57 \mathrm{a}$ & 378 \\
Recife & $0,42 \mathrm{a}$ & 381 & $0,70 \mathrm{~b}$ & 374 \\
Natal & $0,42 \mathrm{a}$ & 379 & $0,64 \mathrm{a}, \mathrm{b}$ & 376 \\
Goiânia & $0,55 \mathrm{~b}, \mathrm{c}$ & 381 & $0,69 \mathrm{~b}$ & 380 \\
\hline Brasil & $\mathbf{0 , 5 2}$ & $\mathbf{2 . 0 0 0}$ & $\mathbf{0 , 7 0}$ & $\mathbf{2 . 0 0 0}$ \\
\hline
\end{tabular}

Fonte: Pesquisa Observatório das Metrópoles, IUPERJ, ICS-UL, ISRP (2006-2008).

Escala: (0) nunca pertenceu a (3) participa ativamente ${ }^{13}$.

Anova: F $(6,2783)=18,341 ; \mathrm{p}<0,001$.

Letras diferentes representam grupos estatisticamente diferentes entre si; letras iguais, grupos não estatisticamente diferentes entre si (Duncan a $\mathrm{p}<0,05$ ).

de socialização para a cidadania vivenciado pelos agentes sociais. Ou seja, existem processos de socialização que incidem sobre as percepções e as atitudes, e que, genericamente, poderiam ser identificados como vivências definidoras da predisposição para a ação política.

Como sintetizam Baquero e Baquero (2007:143), pode-se dizer que os modelos teóricos prevalecentes sobre socialização estão baseados em dois princípios: o princípio da primazia, que sustenta que a "aprendizagem de criança dura toda a vida", e o princípio da estruturação, que defende que "as orientações básicas adquiridas durante a infância estruturam a aprendizagem posterior de crenças sobre assuntos específicos". Em ambas as abordagens, revela-se um "consenso entre os estudiosos deste tema que os valores e normas internalizadas pelas crianças são importantes como determinantes das atitudes quando adultos", ou seja, o comportamento dos agentes tenderia "a revelar uma certa consistência com aquilo que se aprende na infância e na adolescência". Como afirmam Baquero e Baquero (ibidem:143),

quando as crianças alcançam o início da adolescência e chegam à fase pré-adulta, seu sistema de crenças já está enraizado. A partir daí, essas crenças sofrem um processo de diferenciação face à exposição aos meios de comunicação, a novos grupos de referência e ao impacto de 
eventos conjunturais (desemprego, qualidade de vida...) no cotidiano das pessoas.

Assim, os autores concluem que "o comportamento social e político é resultado de um processo de aprendizagem e esta aprendizagem começa na infância e, em muitos sentidos, é complementada na adolescência" (ibidem).

Tendo em vista esse quadro de referência, tomamos como indicador do processo de socialização política - ou seja, como um dos fatores que podem influenciar a predisposição para a ação sociopolítica - a frequência com que se discutia política em casa e/ou na escola, ou na universidade, observando a adolescência e a juventude.

Se considerarmos esse fator um elemento de socialização primária na política, podemos perceber que, em geral, os brasileiros não têm o costume de falar de política, quando jovens, nos espaços onde vivem ou estudam. De fato, na média, os brasileiros raramente discutem política nesses espaços. Nesse tema, comparando-se as cidades brasileiras, mais uma vez se destacaram, situando-se acima da média nacional, as cidades de São Paulo e de Porto Alegre; dessa vez acompanhadas pela cidade do Rio de Janeiro (Tabela 6).

Não obstante a importância dos processos de socialização primária, é preciso levar em conta os novos processos de diferenciação decorrentes da exposição a novos grupos de referência e a novas experiências de vida. Nesse sentido, também é importante avaliar em que medida as pessoas conversam sobre política em seu cotidiano, considerando o local de trabalho; encontros informais com os amigos; a própria casa ou a de seus familiares; reuniões associativas; ou ainda as conversas com os vizinhos. No âmbito da pesquisa, julgamos essas práticas processos de socialização secundária. Em geral, os índices nesse quesito se mostraram muito coerentes com o anterior, acompanhando o baixo grau de socialização primária na política. Em outras palavras, apenas raramente se discute política nesses espaços. Também aqui se destacaram, situando-se acima da média nacional, as cidades de São Paulo e Porto Alegre, novamente acompanhadas pela cidade do Rio de Janeiro (Tabela 6).

Como mencionado anteriormente, outro aspecto importante na construção das percepções em torno da política diz respeito ao acesso e à exposição à mídia informativa. Nesse ponto, é interessante observar as 
Sérgio de Azevedo, Orlando Alves dos Santos Junior e Luiz César de Queiroz Ribeiro

Tabela 6

Socialização Política

Brasil e Cidades Selecionadas - 2006-2008

\begin{tabular}{l|c|c|c|c}
\hline \multirow{2}{*}{ Cidade } & \multicolumn{2}{|c|}{ Socialização Primária } & \multicolumn{2}{c}{ Socialização Secundária } \\
\cline { 2 - 5 } & Média & $\mathbf{N}$ & Média & $\mathbf{N}$ \\
\hline São Paulo & $2,38 \mathrm{~d}$ & 380 & $2,26 \mathrm{~d}$ & 382 \\
Porto Alegre & $2,42 \mathrm{~d}$ & 378 & $2,24 \mathrm{~d}$ & 380 \\
Rio de Janeiro & $2,11 \mathrm{c}$ & 486 & $2,09 \mathrm{c}$ & 496 \\
Belo Horizonte & $1,92 \mathrm{a}$ & 364 & $1,53 \mathrm{a}$ & 383 \\
Recife & $1,92 \mathrm{a}$ & 366 & $2,01 \mathrm{c}$ & 372 \\
Natal & $1,98 \mathrm{a}, \mathrm{b}$ & 362 & $1,89 \mathrm{~b}$ & 378 \\
Goiânia & $2,07 \mathrm{~b}, \mathrm{c}$ & 379 & $2,01 \mathrm{c}$ & 379 \\
\hline Brasil & $\mathbf{2 , 0 6}$ & $\mathbf{1 . 9 7 9}$ & $\mathbf{2 , 0 6}$ & $\mathbf{1 . 9 7 9}$ \\
\hline
\end{tabular}

Fonte: Pesquisa Observatório das Metrópoles, IUPERJ, ICS-UL, ISRP (2006-2008).

Escala: (1) nunca a (4) frequentemente ${ }^{14}$.

Anova: F $(6,2704)=20,287 ; \mathrm{p}<0,001$.

Letras diferentes representam grupos estatisticamente diferentes entre si; letras iguais, grupos não estatisticamente diferentes entre si (Duncan a $\mathrm{p}<0,05$ ).

diferenças entres as cidades brasileiras pesquisadas. Sem grandes surpresas, repete-se o destaque para as cidades de Porto Alegre e São Paulo, cujos moradores aparecem mais expostos à mídia informativa, sendo seguidos, nesse item, pelos moradores de Belo Horizonte. Analisando-se os dados relativos ao Brasil, destaca-se o alto índice alcançado, em todas as cidades, pelo acesso à televisão como principal fonte de informação política. No caso de Porto Alegre, cabe mencionar a alta frequência da leitura de jornais como fonte de informação política, situando-se muito acima das demais cidades brasileiras (Tabela 7). Aqui, devemos levar em conta o impacto diferenciado das diferentes fontes de informação na construção da opinião crítica dos cidadãos, quando consideramos o acesso a informações veiculadas via rádio e televisão, em comparação com diários e revistas semanais, no caso brasileiro agravado pela extrema desigualdade social, que torna a capacidade cognitiva extremamente diferenciada segundo os níveis de escolaridade. Em geral, esses dois últimos meios de comunicação exigem do leitor maior capacidade de abstração e permitem compreensão mais aprofundada da dinâmica política. 
Mudanças e Permanências na Cultura Política das Metrópoles Brasileiras

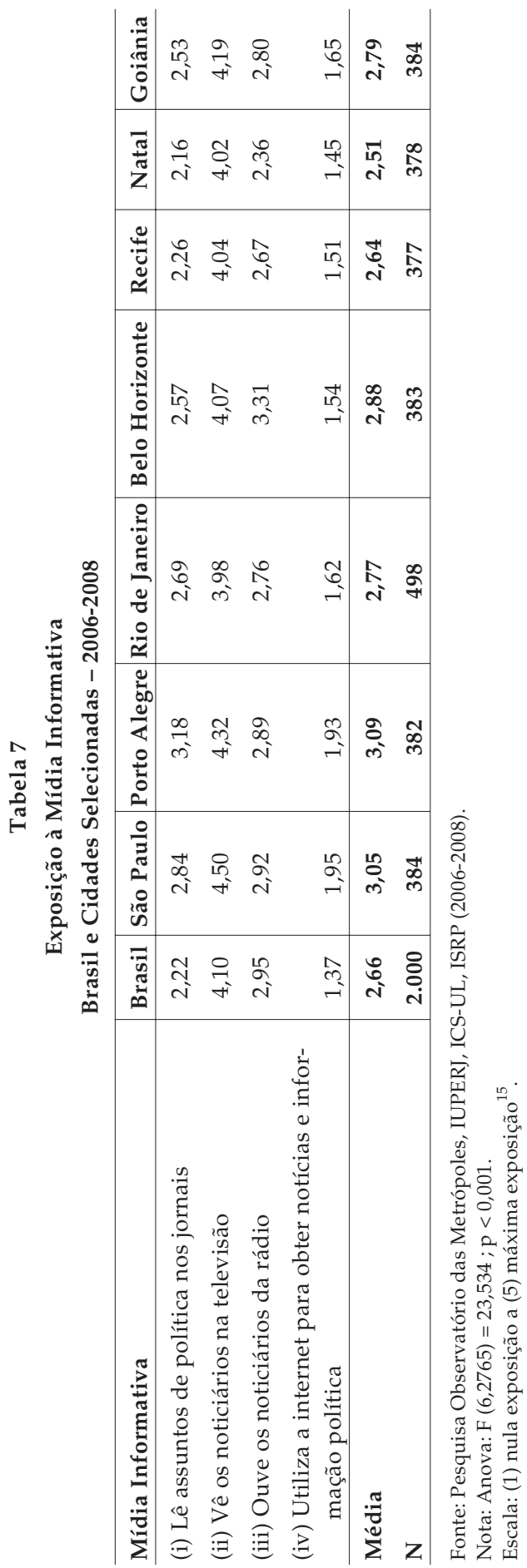




\section{c) Percepção sobre deveres e direitos relativos ao exercício da cidadania}

Quando analisamos as opiniões em torno dos deveres relacionados ao bom exercício da cidadania, podemos perceber a tendência de os brasileiros valorizarem, pelo menos no plano discursivo, práticas comumente relacionadas aos deveres associados ao exercício da cidadania, envolvendo o dever de votar nas eleições, pagar impostos, obedecer às leis, ajudar as pessoas e prestar serviço militar, entre outras questões (Tabela 8).

De forma geral, quando analisamos as médias para o Brasil, destaca-se o fato de que os dois temas menos valorizados foram "escolher os produtos que consome" e, bastante preocupante, "participar em associações, sindicatos e partidos". A relativa menor valorização do primeiro tema talvez possa ser explicada pelo ainda fraco movimento de defesa do consumidor em face dos países do chamado Primeiro Mundo. Por um lado, os avanços institucionais nessa área - entre eles, a criação do Código de Defesa do Consumidor e a criação de órgãos governamentais municipais de defesa do consumidor - têm menos de três décadas. Por outro, em virtude da extrema desigualdade social no Brasil, a maioria da população pobre tenderia a priorizar, em relação à qualidade, o acesso à quantidade dos produtos necessários à sua sobrevivência, o que implica a escolha de mercadorias mais baratas. De qualquer modo, é possível dizer que isso tem mudado de forma incremental. Primeiramente, quanto aos produtos consumidos pela classe média; e, de maneira mais lenta, quanto aos produtos de consumo de massa.

Em relação ao segundo tema, a menor valorização da participação em associações, sindicatos e partidos pode ser explicada tendo em vista as características do sistema político e social brasileiro, no qual o universalismo de procedimentos - ainda que, na qualidade de retórica oficial, venha aumentando, paulatinamente, seu espaço na história republicana do país - é sobrepujado ou apareça entrelaçado por outras gramáticas políticas, como o corporativismo, o clientelismo e, em menor grau, o insulamento burocrático (Nunes, 1997).

No que concerne aos valores com índices mais elevados, destacam-se as opiniões relativas a "ajudar as pessoas necessitadas", tanto brasileiras como de outras partes do mundo. É provável que esse comportamento decorra, sobretudo, do caráter fortemente relacional de nossa sociedade, que, em termos de valores, prioriza as necessidades do gru- 


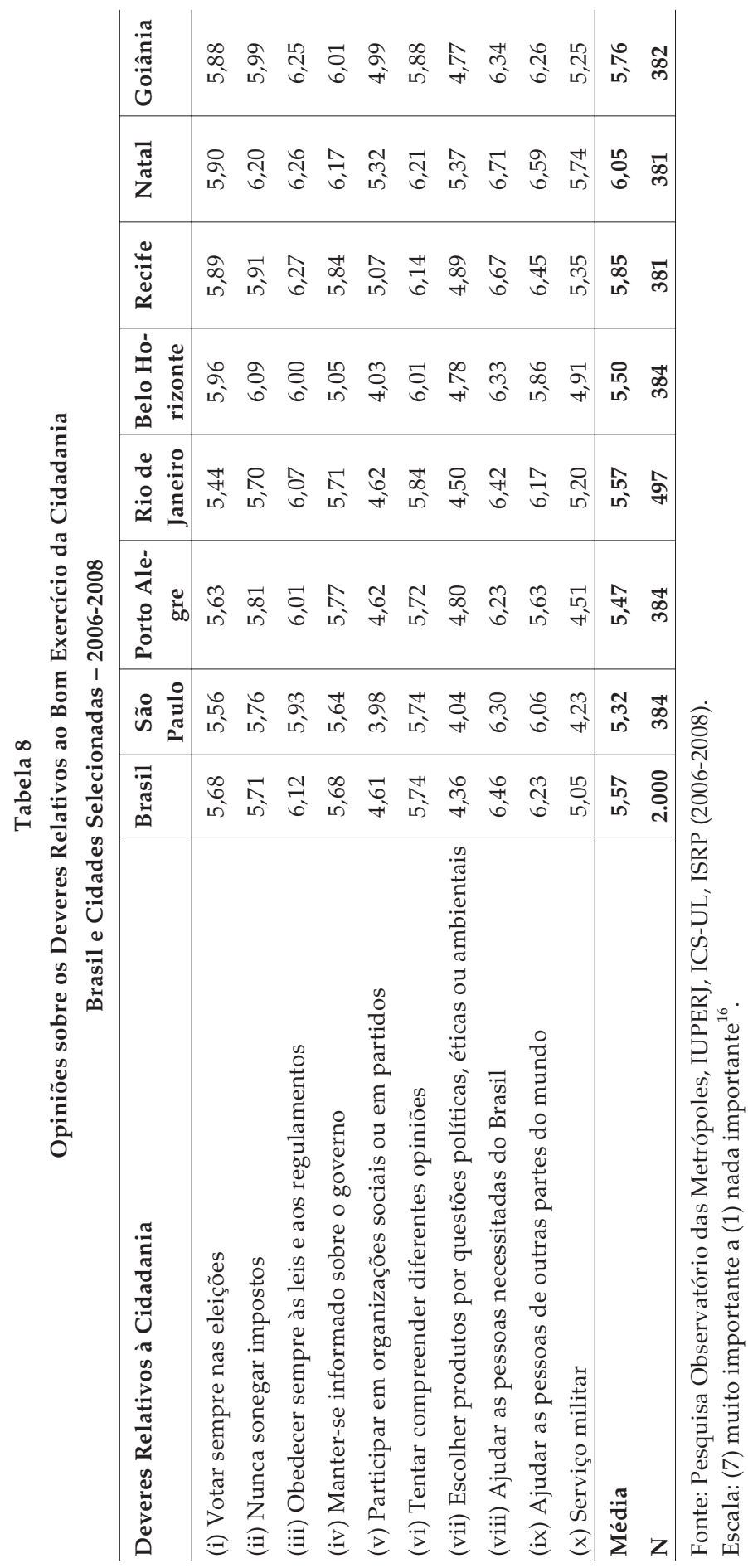


po familiar, em sua perspectiva ampliada - que comportaria, até mesmo, agregados e amigos -, em detrimento de interesses individualistas, vistos como reprováveis socialmente (DaMatta, 1979). Isso permitiria a formação, na esfera da sociabilidade, de redes pessoais de apoio, para os momentos de infortúnio, fortemente ancoradas em vínculos familiares e de vizinhança, mormente para as famílias pobres que habitam as periferias metropolitanas.

Na comparação entre os centros urbanos pesquisados, o que mais chama a atenção são as diferenças que opõem, novamente, as cidades de São Paulo e Porto Alegre - caracterizadas por serem os lugares onde menos se valorizam comportamentos comumente relacionados aos deveres da cidadania moderna - às de Recife, Natal e Goiânia - caracterizadas pela maior valorização dessas mesmas práticas. As cidades do Rio de Janeiro e de Belo Horizonte ocupam um lugar intermediário nessa escala ${ }^{17}$.

Ocorre uma situação similar quando analisamos as opiniões relativas aos direitos de cidadania (Tabela 9). Os brasileiros, em geral, consideram muito importante ter um nível de vida digno, o respeito aos direitos das minorias, o tratamento igualitário, ser escutado e ter mais oportunidades de participação nas decisões de interesse público. No entanto, também nesse caso, podemos perceber que os cidadãos de São Paulo e de Porto Alegre, dessa vez acompanhados pelos de Belo Horizonte, valorizam menos esses temas vinculados aos direitos de cidadania; inversamente, os moradores de Recife, Natal e Goiânia, agora com os do Rio de Janeiro, conferem maior importância a essas questões.

Diante dos valores e das percepções evidenciadas ao longo deste tópico, não é de se estranhar que os brasileiros não demonstrem muito interesse por política, pelo menos da forma como percebem a política oficial no Brasil. Na média, poderíamos definir a posição do brasileiro como sendo de quase nenhum interesse. Coerentes com as diferenças observadas ao longo da análise, novamente São Paulo e Porto Alegre são as capitais que mais se diferenciam da média nacional, ultrapassando a barreira do pouco interesse. De qualquer forma, vale registrar que as cidades de Goiânia, do Recife e do Rio de Janeiro também ficaram levemente acima da média, apesar de distantes dos dois centros anteriormente mencionados (Tabela 10).

Como vimos ao longo desta análise, os indícios de uma polarização entre, de um lado, São Paulo e Porto Alegre, e as demais cidades pesqui- 
Mudanças e Permanências na Cultura Política das Metrópoles Brasileiras

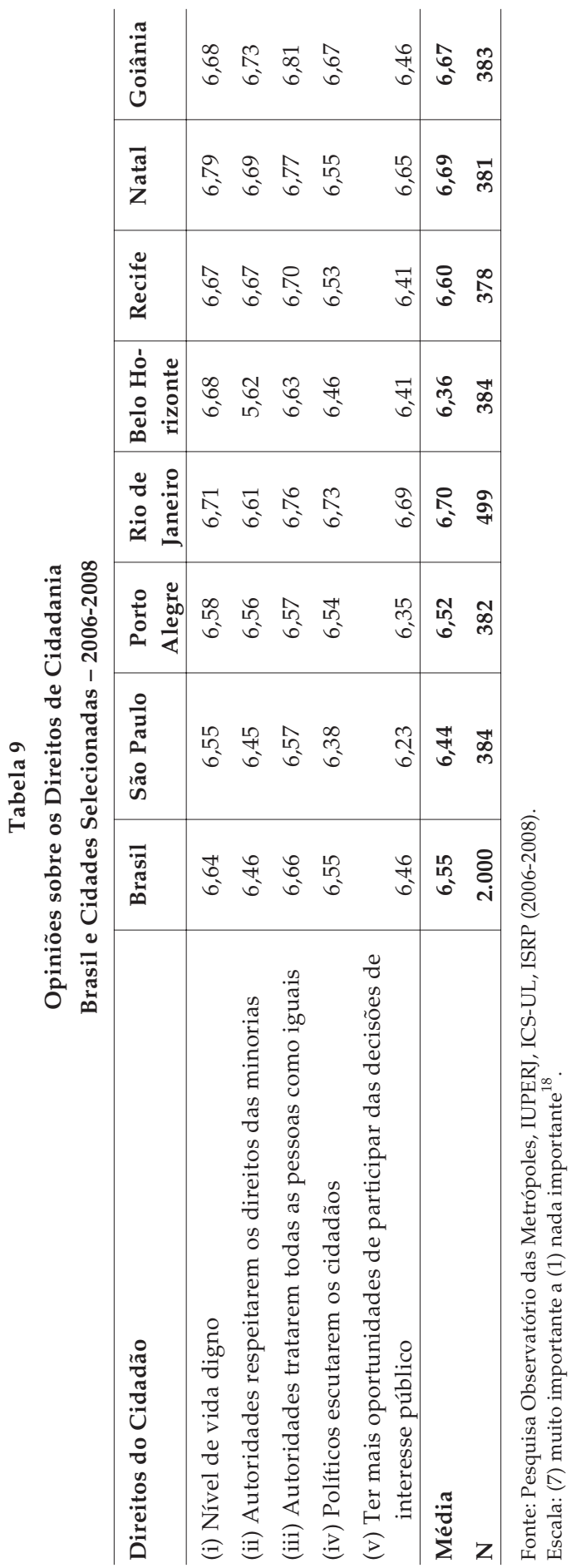


Sérgio de Azevedo, Orlando Alves dos Santos Junior e Luiz César de Queiroz Ribeiro

Tabela 10

Grau de Interesse na Política

Brasil e Cidades Selecionadas - 2006-2008

\begin{tabular}{l|c|c}
\hline Cidade & Média & N \\
\hline São Paulo & $2,29 \mathrm{~d}$ & 381 \\
Porto Alegre & $2,24 \mathrm{~d}$ & 378 \\
Rio de Janeiro & $1,90 \mathrm{~b}$ & 487 \\
Belo Horizonte & $1,65 \mathrm{a}$ & 375 \\
Recife & $1,95 \mathrm{~b}, \mathrm{c}$ & 370 \\
Natal & $1,68 \mathrm{a}$ & 375 \\
Goiânia & $2,07 \mathrm{c}$ & 380 \\
Brasil & 1,88 & 1.954 \\
\hline
\end{tabular}

Fonte: Pesquisa Observatório das Metrópoles, IUPERJ, ICS-UL, ISRP (2006-2008).

Escala: (1) não tem interesse nenhum a (4) muito interessado ${ }^{19}$.

Anova: F $(6,2736)=27,829 ; \mathrm{p}<0,001$.

Letras diferentes representam grupos estatisticamente diferentes entre si; letras iguais, grupos não estatisticamente diferentes entre si. Duncan a $\mathrm{p}<0,05$.

sadas, de outro, possibilitam levantar a hipótese de que as mudanças no comportamento e nos valores culturais estão relacionadas ao dinamismo econômico, político e social dos centros urbanos considerados e aos processos de relativo enfraquecimento dos valores clássicos relacionados ao bom exercício da cidadania nesses espaços, que combinam tradição sindical e de participação cívica com mudanças socioculturais relacionadas aos processos de globalização contemporânea.

\section{CONSIDERAÇÕES FINAIS: CULTURAS POLÍTICAS ENTRELAÇADAS}

Parece inegável que, sobretudo a partir dos anos 1980, a agenda política dos movimentos sociais brasileiros se tornou mais complexa e diversificada, acompanhando a dinâmica dos movimentos sociais, alargando as reivindicações urbanas e inserindo, na agenda pública, questões relacionadas às desigualdades de gênero, às desigualdades étnico-raciais, ao meio ambiente, à mobilidade urbana, aos direitos da criança e do adolescente, à liberdade sexual, à economia solidária, entre outros tantos temas, expressando uma agenda social e política cada vez menos pautada por reivindicações estritamente materiais - reivindicações salariais, distribuição de renda e acesso aos equipamentos urbanos. As transformações na dinâmica urbana e o processo de metropolização verificado no Brasil certamente também se constituem em importante substrato das mudanças ocorridas em nossa cultura políti- 
ca. No entanto, apesar de reconhecermos a crescente importância de demandas relacionadas às concepções e aos modos de vida defendidos por diferentes grupos sociais, não devemos subestimar a permanência dessas demandas e das reivindicações materiais, sobretudo em uma sociedade com elevados níveis de desigualdades sociais, como a brasileira.

Uma questão central diz respeito, como verificamos ao longo deste artigo, à existência de diferenças significativas na cultura política dos brasileiros quando consideramos as diferentes cidades metropolitanas do país. Essas diferenças parecem indicar a existência de uma relação direta entre as dinâmicas urbana e socioeconômica, de um lado, e a adoção de padrões de comportamento relacionados à NCP, de outro. No caso brasileiro, dois centros metropolitanos - Porto Alegre e São Paulo - se sobressaem, pelo fato de se aproximarem, comparativamente, mais desse padrão do que as demais cidades consideradas, com seus cidadãos expressando opiniões, valores e atitudes associados à NCP. Quanto a todos os demais centros metropolitanos analisados Rio de Janeiro, Belo Horizonte, Recife, Goiânia e Natal -, porém, é possível dizer que há sinais de comportamentos similares, mesmo que restritos a pequenos grupos sociais; em geral, com maior nível de renda e de escolaridade.

A nosso ver, valores e comportamentos relacionados à NCP no Brasil, mesmo que se tenham fortalecido nas últimas décadas, estão longe de se constituírem na principal gramática cultural existente. Além disso, a gramática cultural clássica (esquerda e direita tradicionais) nunca alcançou os níveis dos países ocidentais desenvolvidos. Por outro lado, vertentes híbridas, como o clientelismo, em suas diferentes formas (tradicional e mediada por máquinas políticas controladas por líderes carismáticos), e o corporativismo, apresentam-se com grande pujança. Por fim, há experimentos de organização popular e de sindicalismo fundados no fortalecimento da autonomia e no protagonismo de seus integrantes, além da criação de partidos políticos programáticos, de base sindical e popular. Nesse sentido, poderíamos dizer que, no Brasil, há um entrelaçamento de múltiplas gramáticas culturais criando cenários extremamente diversificados de percepções, valores e comportamentos dos agentes sociais.

Nesse contexto, há que se refletir em que medida as mudanças evidenciadas podem ser satisfatoriamente explicadas pela teoria da NCP. De 
fato, há transformações na cultura política, mas talvez elas estejam menos relacionadas ao suposto desenvolvimento de uma agenda pós-materialista e mais vinculadas a algum tipo de relação com a emergência de modos flexíveis de acumulação do capital (Harvey, 1993) e a "reorientação das posturas das governanças urbanas adotadas nas últimas duas décadas" (idem, 2005:167), disseminando-se em todos os países capitalistas.

Assim, inspirados na análise de Harvey sobre a condição pós-moderna, poderíamos formular a hipótese de que essas mudanças, quando confrontadas com a cultura política associada a instituições liberais republicanas, se mostram mais vinculadas às transformações na dinâmica inerente a essas instituições - com sua crescente incapacidade de representação política da multiplicidade de interesses existentes na sociedade e sua atual crise de legitimidade - do que à expressão de alguma nova cultura pós-materialista ou mesmo pós-liberal inteiramente nova.

Ao longo deste ensaio exploratório, problematizamos as formas pelas quais, no Brasil, estariam sendo incorporadas as mudanças econômicas e culturais decorrentes da globalização contemporânea e discutimos seus impactos na cultura política. Assim, buscamos refletir em que medida as concepções e os comportamentos associados à NCP se aproximariam da cultura política dos brasileiros, destacando alguns centros urbanos metropolitanos como espaços sociais onde se poderiam observar, mais explicitamente, essas mudanças, em razão do efeito metrópole.

Estamos conscientes de que os desafios que se apresentam nessa empreitada não podem ser subestimados, motivo pelo qual acreditamos que os avanços serão incrementais e acumulativos. Ainda que muito instigante, o conceito de $\mathrm{NCP}$, tanto no que se refere à sua robustez teórica como no que se refere à sua aplicação a países emergentes, como o Brasil, merece ser discutido tendo em vista suas possibilidades e limites na identificação e na explicação das mudanças em curso na contemporaneidade.

(Recebido para publicação em novembro de 2007) (Versão definitiva em julho de 2009) 


\section{NOTAS}

1. Apesar de o escopo deste artigo estar centrado no debate sobre o Brasil, entendemos, naturalmente, que a discussão sobre a pertinência do conceito de NCP pode ser realizada também para os chamados países do Primeiro Mundo, questionando os pressupostos e as conclusões alcançadas pelos autores já citados.

2. As pesquisas foram realizadas pela Rede Observatório das Metrópoles no âmbito do projeto Milênio. Na etapa nacional, a pesquisa de campo foi desenvolvida em parceria com o Instituto Universitário de Pesquisas do Rio de Janeiro (IUPERJ); nas demais metrópoles, apenas pela Rede Observatório das Metrópoles. Em seu conjunto, as pesquisas estão incluídas nas redes do International Survey Research Programme (ISRP) e da European Social Survey (ESS). Cabe ressaltar ainda que foi realizado um convênio com o Instituto de Ciências Sociais da Universidade de Lisboa (ICS-UL) em virtude de um projeto comparativo sobre a análise das atitudes sociais de brasileiros e portugueses.

3. Clark vem analisando, durante os últimos trinta anos, a evolução da cultura política no âmbito local, concluindo que as tendências de emergência de uma "nova cultura política" estariam se consolidando até em partidos políticos de caráter nacional (Clark e Inglehart, 2007). Na visão de seus formuladores, a NCP constituiria uma transformação de caráter societal de normas e valores, derivada de mudanças nas estruturas socioeconômicas das sociedades desenvolvidas e tendo como um de seus resultados a erosão das formas tradicionais de interação cívica e social. Assim, as mudanças de normas e valores afetariam não somente os conteúdos da agenda (temas materialistas, com base em clivagens das classes, esquerda/direita etc.), como também engendram uma combinação de atitudes conservadoras, no que diz respeito a temas fiscais e sociais, acopladas a comportamentos liberais progressistas em relação aos costumes e estilos de vida, além da adoção de novas formas de ação política (Clark e Navarro, 2007).

4. Estabelecendo um paralelo com o Norte e o Sul da Itália, o autor afirma que, diferentemente dos Estados Unidos, que se teriam beneficiado da tradição inglesa de civismo, os países da América Latina teriam sido prejudicados pelo autoritarismo, pela exploração e pela dependência legados pela colonização ibérica, em uma herança que marcou, definitivamente, a trajetória dos países aí situados (Putnam, 1996).

5. Esse processo de regulação do mercado pelo Estado é inerente ao próprio capitalismo. Como destaca Polanyi (2000:84), "subordinar a substância da própria sociedade às leis do mercado" resultaria no desmoronamento da sociedade. Segundo o autor, essa ameaça torna inevitável o surgimento (como ocorreu ao longo dos séculos XIX e $\mathrm{XX)}$ de alguma forma de protecionismo que limite o poder do livre mercado: "Despojados da cobertura protetora das instituições culturais, os seres humanos sucumbiriam sob os efeitos do abandono social" (ibidem:85). É para proteger a sociedade "desse moinho satânico" (ibidem:86) que surgem os contramovimentos de proteção social. De fato, até as próprias transações capitalistas devem ser também protegidas do funcionamento irrestrito do mercado.

6. Os exemplos são por demais evidentes. Para não alongar a lista, o caso da China é ilustrativo, com a introdução de uma forte economia de mercado nas "zonas especiais" e nas grandes metrópoles, convivendo com o discurso da construção do socialismo adaptado às condições chinesas. 
7. Para DaMatta (1979), há, na sociedade brasileira, uma distinção entre "pessoa" - digna de consideração quando a interpretação da lei é matizada de forma favorável - e "indivíduo" - que não possui relações privilegiadas, correndo o risco de ser tratado com os rigores da lei.

8. Na amostra nacional, foram entrevistadas 2.000 pessoas; e, complementarmente, mais 2.804 pessoas, distribuídas pelas seguintes cidades: São Paulo (384), Rio de Janeiro (500), Porto Alegre (384), Belo Horizonte (384), Recife (384), Natal (384) e Goiânia (384). No que se refere à amostra nacional, temos $51,2 \%$ de mulheres e $48,9 \%$ de homens, todos maiores de 18 anos, distribuídos entre as seguintes faixas etárias: $34,6 \%$ entre 18 e 29 anos; $31,6 \%$ entre 30 e 44 anos; $19,9 \%$ entre 45 e 59 anos; $11,8 \%$ entre 60 e 74 anos; e 2,2\% com mais de 75 anos. A maior parte dos entrevistados é solteira (49\%), mas também é significativo o percentual de casados (37\%). A amostra também contou com $7 \%$ de viúvos e 7\% de separados ou divorciados. Em geral, o nível de escolaridade dos entrevistados é baixo, prevalecendo pessoas que cursaram até o nível médio incompleto ( $68 \%$ da amostra).

9. A pergunta da entrevista foi: "Por vezes, as pessoas participam de grupos ou de associações. Para cada um dos grupos mencionados, diga se: (a) participa ativamente; (b) pertence, mas não participa ativamente; (c) já pertenceu; (d) nunca pertenceu". Considerou-se a participação em partidos políticos; sindicato, grêmio ou associação profissional; igreja ou organismo religioso; grupo desportivo, recreativo ou cultural; e outras associações voluntárias.

10. Considerou-se, na pesquisa, como expressão da mobilização sociopolítica, a participação nas seguintes atividades: assinatura de abaixo-assinados; boicote a produtos por questões políticas, éticas e ambientais; manifestações políticas; comícios; contato com políticos ou altos funcionários do Estado; doações de dinheiro ou recolhimento de fundo para causas públicas; contato com a mídia; e fóruns pela internet.

11. No questionário, a pergunta foi formulada da seguinte forma: "Abaixo são listadas algumas formas de ação política e social que as pessoas podem ter. Por favor, indique, para cada uma delas se: (1) fez no último ano; (2) fez em anos anteriores; (3) nunca fez, mas poderia ter feito; (4) nunca o faria. Formas de ação política e social: assinar uma petição ou fazer um abaixo-assinado; boicotar ou comprar determinados produtos por questões políticas, éticas ou ambientais; participar em uma manifestação; participar em um comício ou em uma reunião política; contactar, ou tentar contactar, um político ou um funcionário do governo para expressar seu ponto de vista; dar dinheiro ou tentar recolher fundos para uma causa pública; contactar ou aparecer na mídia para exprimir suas opiniões; participar em um fórum ou em um grupo de discussão pela internet".

12. Para controlarmos, estatisticamente, a comparação das médias dos índices para cada cidade, realizamos uma análise de variância (Anova) para distinguirmos médias que não se diferenciam, significativamente, e formamos grupos de médias que diferenciam, significativamente, entre si.

13. Os índices de associativismo e de mobilização foram construídos com base nas médias das respostas das questões relativas a cada um dos índices (ver Tabelas 1 e 2), tendo como resultado um índice que varia de 0 a 3.

14. Na socialização primária, o índice corresponde à média alcançada em duas perguntas: "(i) quando o(a) senhor(a) tinha 14/15 anos, com que frequência se falava de polí- 
tica em sua casa?; (ii) na escola/ universidade, com que frequência se fala, ou se falava, de política?". Na construção do índice, foram dados pesos diferenciados, de acordo com as seguintes respostas: "(4) frequentemente; (3) algumas vezes; (2) raramente; e (1) nunca". Na socialização secundária, o índice corresponde à média alcançada em uma pergunta dividida em cinco itens: "Hoje em dia, fora dos meios de comunicação (televisão, rádio e jornais), com que frequência ouve falar de assuntos políticos em cada um dos seguintes locais: (i) local de trabalho; (ii) encontros com os amigos; (iii) a própria casa ou a de seus familiares; (iv) reuniões associativas; (v) conversas com os vizinhos. Na construção do índice, foram dados pesos diferenciados de acordo com as seguintes respostas: (4) frequentemente; (3) algumas vezes; (2) raramente; e (1) nunca".

15. O índice corresponde à média alcançada para a seguinte pergunta: "Com que frequência o(a) senhor(a) faz cada uma das seguintes coisas?: (i) lê assuntos de política nos jornais; (ii) vê os noticiários na televisão; (iii) ouve os noticiários da rádio; (iv) utiliza a internet para obter notícias e informação política. Sendo: (5) todos os dias; (4) 3-4 dias por semana; (3) 1-2 dias por semana; (2) menos de 1 dia por semana; e (1) nunca".

16. A pergunta do questionário era a seguinte: "Há muitas opiniões diferentes sobre o que se deve fazer para ser um bom cidadão. Em uma escala de 1 a 7 , em que 1 significa nada importante e 7 muito importante, que importância o(a) senhor(a) atribui, pessoalmente, a cada um dos seguintes aspectos: (i) votar sempre nas eleições; (ii) nunca sonegar impostos; (iii) obedecer sempre às leis e aos regulamentos; (iv) manter-se informado sobre as atividades do governo; (v) participar em associações, sindicatos e partidos; (vi) tentar compreender a maneira de pensar das pessoas com opiniões diferentes das suas; (vii) escolher produtos por questões políticas, éticas ou ambientais, mesmo que eles custem mais caro; (viii) ajudar as pessoas que, no Brasil, vivem pior do que o(a) senhor(a); (ix) ajudar as pessoas que, no resto do mundo, vivem pior do que o(a) senhor(a); e (x) estar disposto a prestar serviço militar quando for preciso".

17. Se considerarmos apenas as médias gerais, Rio de Janeiro e Belo Horizonte se aproximam das cidades de São Paulo e Porto Alegre, mas, de fato, olhando os diferentes componentes da pesquisa, percebe-se que as duas primeiras flutuam fortemente na importância atribuída aos diferentes valores.

18. A pergunta do questionário foi a seguinte: “Há muitas opiniões diferentes sobre os direitos das pessoas em uma democracia. Nesta escala de 1 a 7 , em que 1 significa sem importância e 7 muito importante, que importância o(a) senhor(a) atribui a: (i) todos os cidadãos terem um nível de vida digno; (ii) as autoridades respeitarem e protegerem os direitos das minorias; (iii) as autoridades tratarem todas as pessoas da mesma maneira, independentemente de sua posição social; (iv) os políticos escutarem os cidadãos antes de tomarem decisões; e (v) dar às pessoas mais oportunidades de participar nas decisões de interesse público".

19. A pergunta do questionário foi: “O(A) senhor(a) diria que é interessado(a) em política? Sendo: (4) muito interessado; (3) interessado; (2) não muito interessado; e (1) não tem interesse nenhum". 


\section{REFERÊNCIAS BIBLIOGRÁFICAS}

AZEVEDO, Sérgio de e MARES GUIA, Virgínia Rennó dos. (2001), “O Orçamento Participativo como Política Pública: Reflexões sobre o Caso de Belo Horizontes". Caderno CRH, no 35, pp. 179-197.

BAQUERO, Rute e BAQUERO, Marcelo. (2007), "Educando para a Democracia: Valores Democráticos Partilhados por Jovens Porto-Alegrenses". Ciências Sociais em Perspectiva, vol. 6, no 11, pp. 139-153.

BAUMAN, Zygmunt. (1998), O Mal-Estar da Pós-Modernidade. Rio de Janeiro, Zahar (tradução de Mauro Gama e Cláudia M. Gama).

. (1999), Globalização: As Conseqüências Humanas. Rio de Janeiro, Zahar (tradução de Marcus Penchel).

BOSCHI, Renato. (2004), “Instituciones Políticas, Reformas Estructurales y Ciudadanía: Dilemas de la Democracia en Brasil”. Revista Política, vol. 42, pp. 281-308.

CABRAL, Manuel Villaverde. (2000), "O Exercício da Cidadania Política em Portugal”, in M. V. Cabral, J. Vala e J. Freire (orgs.), Trabalho e Cidadania. Lisboa, Imprensa de Ciências Sociais, pp. 123-162.

e SILVA, Filipe Carreira da. (2007), “Ciudad y Ciudadanía en Portugal. El 'Efecto-Metrópolis' sobre el Ejercicio de la Ciudadanía Política”, in T. N. Clark e C. J. Navarro (eds.), La Nueva Cultura Política: Tendencias Globales y Casos Iberoamericanos. Madrid, Miño y Dávila, pp. 331-334.

CASTEL, Robert. (1998), As Metamorfoses da Questão Social: Uma Crônica do Salário. Petrópolis, Vozes (tradução de Iraci D. Poleti).

CASTELLS, Manuel. (1985), “Reestructuración Económica, Revolución Tecnológica y Nueva Organización del Territorio", in M. Castells et alii, Metrópolis, Território y Crisis. Madrid, Asamblea de Madrid.

CLARK, Terry N. e HOFFMANN-MARTINOT, Vincent. (1998), The New Political Culture. Boulder, Westview Press.

CLARK, Terry N. e INGLEHART, Ronald. (2007), “La Nueva Cultura Política: Cambios en el Apoyo al Estado del Bienestar y otras Políticas en las Sociedades Post-Industriales", in T. N. Clark e C. J. Navarro (eds.), La Nueva Cultura Política: Tendencias Globales y Casos Iberoamericanos. Madrid, Miño y Dávila, pp. 51-132.

CLARK, Terry N. e NAVARRO, Clemente J. (2007), La Nueva Cultura Política: Tendencias Globales y Casos Iberoamericanos. Madrid, Miño y Dávila.

DAHL, Robert A. (1997), Poliarquia: Participação e Oposição. São Paulo, Edusp (tradução de Celso Mauro Paciornik).

DAMATTA, Roberto. (1979), Carnavais, Malandros e Heróis: Para uma Sociologia do Dilema Brasileiro. Rio de Janeiro, Zahar.

DAVIDOVICH, Fany. (2001), Metrópoles no Brasil: Escalas e Questões. Trabalho apresentado no XXV Encontro Anual da Associação Nacional de Pós-Graduação e Pesquisa em Ciências Sociais (Anpocs), Caxambu, 16-20 de outubro. 
FERES JÚNIOR, João e EISENBERG, José. (2006), “Dormindo com o Inimigo: Uma Crítica ao Conceito de Confiança". DADOS, vol. 49, no 3, pp. 457-481.

FRASER, Nancy e HONNETH, Axel. (2003), Redistribution or Recognition? A Political-Philosophical Exchange. London, Verso.

HARVEY, David. (1993), Condição Pós-Moderna. São Paulo, Edições Loyola (tradução de Adail Ubirajara Sobral e Maria Stela Gonçalves).

. (2004), Espaços de Esperança. São Paulo, Edições Loyola (tradução de Adail Ubirajara Sobral e Maria Stela Gonçalves).

. (2005), A Produção Capitalista do Espaço. São Paulo, Annablume.

HOBSBAWM, Eric. (1995), Era dos Extremos: O Breve Século XX (1914-1991) (2a ed.). São Paulo, Companhia das Letras (tradução de Marcos Santarrita).

IBGE (Instituto Brasileiro de Geografia e Estatística). (1997), Associativismo, Representação de Interesses e Intermediação Política. Rio de Janeiro, IBGE.

INGLEHART, Ronald. (1999), “Trust, Well-Being and Democracy”, in M. E. Warren (ed.), Democracy and Trust. Cambridge, Cambridge University Press, pp. 88-120.

LEVI, Margaret. (1996), “Uma Lógica da Mudança Institucional”. DADOS, vol. 34, no 1, pp. 79-99.

MARSHALL, Thomas Humphrey. (1967), Cidadania, Classe Social e Status. Rio de Janeiro, Zahar (tradução de Meton Porto Gadelha).

MOISÉS, José Álvaro. (1992), “Democratização e Cultura de Massas no Brasil”. Lua Nova, no 26, pp. 5-51.

NUNES, Edson. (1997), A Gramática Política do Brasil: Clientelismo e Insulamento Burocrático. Rio de Janeiro/Brasília, Zahar/Enap.

O’DONNELL, Guillermo. (1999), “Teoria Democrática e Política Comparada”. DADOS, vol. 42, no 4 , pp. 577-654.

OLSON, Mancur. (1999), A Lógica da Ação Coletiva: Os Benefícios Públicos e uma Teoria dos Grupos Sociais. São Paulo, Edusp.

OSBORNE, David e GAEBLER, Ted. (1992), Reinventing Government: How The Entrepreneurial Spirit is Transforming the Public Sector. New York, Addison-Wesley.

POLANYI, Karl. (2000), A Grande Transformação: As Origens da Nossa Época (11à ed.). Rio de Janeiro, Elsevier.

PUTNAM, Robert D. (1996), Comunidade e Democracia: A Experiência da Itália Moderna. Rio de Janeiro, Editora FGV (tradução de Luiz Alberto Monjardim).

. (2000), Bowling Alone: The Collapse and Revival of American Community. New York, Simon \& Schuster.

REIS, Fábio Wanderley. (1988), “Consolidação Democrática e Construção do Estado: Notas Introdutórias e uma Tese”, in F. W. Reis e G. O'Donnell (orgs.), A Democracia no Brasil: Dilemas e Perspectivas. São Paulo, Vértice. (2000), Mercado e Utopia: Teoria Política e Sociedade Brasileira. São Paulo, Edusp. 
Sérgio de Azevedo, Orlando Alves dos Santos Junior e Luiz César de Queiroz Ribeiro

RIBEIRO, Luiz César de Queiroz e SANTOS JUNIOR, Orlando Alves dos. (1996), Associativismo e Participação Popular: Tendências da Organização Popular no Rio de Janeiro. Rio de Janeiro, IPPUR/UFRJ-Fase.

. (2007), “As Metrópoles Brasileiras: Territórios Desgovernados", in L. C. de Q. Ribeiro e O. A. dos Santos Junior (orgs.), As Metrópoles e a Questão Social Brasileira. Rio de Janeiro, Revan/Fase, pp. 7-17.

SANTOS, Wanderley Guilherme dos. (1993), As Razões da Desordem. Rio de Janeiro, Rocco.

SARTORI, Giovanni. (1994), A Teoria da Democracia Revisada. São Paulo, Ática.

SIMMEL, Georg. (1979), “A Metrópole e a Vida Mental”, in O. Velho (org.), O Fenômeno Urbano. Rio de Janeiro, Zahar, pp. 11-25.

SOUZA, Jessé de. (2000), A Modernização Seletiva: Uma Reinterpretação do Dilema Brasileiro. Brasília, Ed. da UnB.

. (2003), A Construção Social da Subcidadania: Para uma Sociologia Política da Modernidade Periférica. Belo Horizonte/Rio de Janeiro, Ed. da UFMG/IUPERJ.

TAYLOR, Charles. (1992), "The Politics of Recognition", in C. Taylor e A. Gutmann (eds.), Multiculturalism: Examining the Politics of Recognition. Princeton, Princeton University Press.

TOURAINE, Alain. (1995), O Brasil frente aos Desafios da Globalização. Trabalho apresentado na Faculdade de Filosofia e Ciências Humanas, UFMG. Manuscrito.

TURNER, Bryan. (1990), "Outline of a Theory of Citizenship". The Journal of the British Sociological Association, vol. 24, no 2 .

WEBER, Max. (1999), Economia e Sociedade: Fundamentos da Sociologia Compreensiva. Brasília/São Paulo, UnB/Imprensa Oficial do Estado.

. (2004), A Ética Protestante e o Espírito do Capitalismo. São Paulo, Martin Claret (tradução de Pietro Nassetti). 


\begin{abstract}
Change and Permanence in the Political Culture of Brazilian Metropolises

This article discusses the formulations of the theoretical school known as the New Political Culture (NPC), seeking to evaluate the limits and possibilities of this approach for interpreting contemporary Brazilian culture. Based on research by the Network of Metropolitan Observatories in partnership with other Brazilian and international institutions, the authors argue that this approach is limited in its ability to analyze current changes in Brazil, where the values and behaviors related to NPC, although gaining strength in recent decades, are far from constituting the main existing cultural grammar.
\end{abstract}

Key words: political culture; metropolises; new political culture; citizenship; associativism

\title{
RÉSUMÉ
}

Changements et Permanences dans la Culture Politique des Métropoles Brésiliennes

Dans cet article, on discute les concepts du courant théorique nommé Nouvelle Culture Politique (NCP), cherchant à évaluer les limites et possibilités de cette aproche dans l'interprétation de la culture politique brésilienne contemporaine. À partir d'une recherche effectuée par le Réseau Observatoire des Métropoles, en association avec d'autres institutions nationales et internationales, on considère que cette approche reste limitée lorsqu'il s'agit d'analyser les transformations qui ont lieu au Brésil, où les valeurs et comportements proches de la NCP, bien que se renforçant depuis quelques décennies, sont encore loin de devenir la grammaire culturelle predominante du pays.

Mots-clé: culture politique; métropoles; nouvelle culture politique; citoyenneté; associativisme 